\title{
Synthesis of novel fluorinated polymers: facile carbon- carbon bond formation aided by fluorine substituents
}

\author{
Tadashi Narita
}

The review article summarizes my work as a macromolecular synthetic chemist to leave it on the sands of time. Fluorinated vinyl compounds with high addition reactivities toward anionic and radical species were demonstrated to allow facile preparation of fluorinated polymers. Novel anionic addition polymerization of fluorinated vinyl monomers, which generally show poor homopolymerization reactivities under radical conditions, has been developed. Measurement of pseudo first-order rate constants, $K$, demonstrated the order of reactivity of 18 fluorinated acrylates and methacrylates by the reaction with diethyl(ethyl cyanoacetato)aluminum. The new field, anionic polyaddition, was accomplished by the double Michael addition of bis(2-trifluoromethylacrylate)s to active methylene compounds. Radical addition reaction of several fluorinated vinyl compounds with organic compounds possessing carbon-hydrogen bonds afforded fluorinated organic compounds. By developing the novel radical addition, the polyaddition reaction was achieved to incorporate fluorinated vinyl monomers into polymer main chains with organic compounds possessing carbon-hydrogen bonds, the first use for these polymers as starting materials of macromolecular syntheses. Facile carbon-carbon bond formation reactions were made possible with the aid of fluorine substituents under anionic and radical conditions. These reactions were then developed into the formation of the carbon-carbon bond from a carbon-hydrogen bond as a functional group in aliphatic compounds.

Polymer Journal (2011) 43, 497-515; doi:10.1038/pj.2011.30; published online 27 April 2011

Keywords: addition reaction; anionic polyaddition; anionic polymerization; double Michael addition; fluoropolymer; radical polyaddition; radical polymerization

\section{INTRODUCTION}

The Clarke number of fluorine is about $0.03 \%$, which is about half of that of sulfur, one-sixth of that of chlorine and almost equal to that of nitrogen and rubidium. This suggests that fluorine should be one of the most abundant elements on the Earth. The fluorine atom has two well-known distinguishing characteristics: it is the smallest element except for hydrogen, and it has the highest electron-withdrawing ability of all the elements. All hydrogens linked to carbons in organic compounds could theoretically be substituted by fluorine atoms. Replacing the hydrogens of poly(ethylene) with fluorines yields poly(tetrafluoroethylene). The $e$-values of fluorinated vinyl monomers are generally larger than those of the hydrocarbon analogs because of the high electron-withdrawing inductive effect of fluorine substituents.

The synthesis of fluorinated polymer began with the discovery of poly(tetrafluoroethylene) by Plunkett in 1938, although the synthesis of poly(chlorotrifluoroethylene) was reported by Schlöffer and Scherer in 1934. ${ }^{1}$ The history of fluorinated polymer syntheses is as long as that of hydrocarbon analogs, as poly(ethylene) was synthesized under high pressure in 1933, Nylon-66 was synthesized by Carothers in 1936 and in 1952 poly(ethylene) was synthesized by Ziegler under low pressure, earning him the Nobel Prize. Staudinger was the first Nobel laureate in macromolecular chemistry, and the award marks it as one of the most essential sciences.

The homopolymerization reactivity of polyfluorinated vinyl monomers is well known to be very poor except for tetrafluoroethylene and chlorotrifluoroethylene. Another commercially available polyfluorinated homopolymer is poly(vinylidene fluoride). Further, copolymerizations of several polyfluorinated vinyl monomers have been studied with hydrocarbon analogs, and quite a few fluorine-containing copolymers are commercially available. The study on the polymerization and copolymerization of fluorinated vinyl monomers has predominantly focused on radical addition polymerization, and a great deal of information on these reactions is available from patents because the research and the development have mainly been carried out by industrial research groups. ${ }^{1}$

Radical addition polymerization of typical fluorinated vinyl monomers seems to have been thoroughly studied. The homopolymerization reactivities of fluorinated vinyl monomers bearing perfluorovinyl groups $\left(\mathrm{CF}_{2}=\mathrm{CF}-\right)$ such as trifluorovinylbenzene $\left(\mathrm{CF}_{2}=\mathrm{CF}-\mathrm{C}_{6} \mathrm{H}_{5}\right)$ and hexafluoro-1,3-butadiene $\left(\mathrm{CF}_{2}=\mathrm{CF}-\mathrm{CF}=\mathrm{CF}_{2}\right)$ are very low. The polymerization reactivities of $\alpha$-trifluoromethylvinyl $\left(\mathrm{CH}_{2}=\mathrm{C}\left(\mathrm{CF}_{3}\right)_{-}\right)$ 
Table $1 Q$ and $e$-values of fluorinated acrylate

\begin{tabular}{|c|c|c|}
\hline Monomer & $Q$ & $e$ \\
\hline $\mathrm{CH}_{2}=\mathrm{CH}-\mathrm{COOCH}_{2} \mathrm{CF}_{2} \mathrm{CF}_{2} \mathrm{CF}_{3}$ & 0.78 & 1.15 \\
\hline $\mathrm{CH}_{2}=\mathrm{CH}-\mathrm{COOCH}_{2} \mathrm{CF}_{3}$ & 0.97 & 1.13 \\
\hline $\mathrm{CH}_{2}=\mathrm{CH}-\mathrm{COOCH}\left(\mathrm{CF}_{3}\right)_{2}$ & 0.79 & 1.36 \\
\hline $\mathrm{CH}_{2}=\mathrm{C}\left(\mathrm{CH}_{3}\right)-\mathrm{COOCH}_{2} \mathrm{CF}_{3}$ & 1.03 & 0.98 \\
\hline $\mathrm{CH}_{2}=\mathrm{C}\left(\mathrm{CH}_{3}\right)-\mathrm{COOCH}\left(\mathrm{CF}_{3}\right)_{2}$ & 1.38 & 1.30 \\
\hline \multirow[t]{2}{*}{$\mathrm{CH}_{2}=\mathrm{CF}-\mathrm{COOCH}$} & 0.92 & 1.33 \\
\hline & 0.47 & 0.73 \\
\hline \multirow[t]{2}{*}{$\mathrm{CH}_{2}=\mathrm{CF}-\mathrm{COOC}_{2} \mathrm{H}_{5}$} & 0.66 & 1.06 \\
\hline & 0.49 & 0.68 \\
\hline $\mathrm{CH}_{2}=\mathrm{C}\left(\mathrm{CF}_{3}\right)-\mathrm{COOCH}_{3}$ & 0.8 & 2.9 \\
\hline $\mathrm{CH}_{2}=\mathrm{C}\left(\mathrm{CF}_{3}\right)-\mathrm{CN}$ & 2.5 & 3.1 \\
\hline $\mathrm{CH}_{2}=\mathrm{CH}-\mathrm{COOCH}_{3}$ & 0.42 & 0.6 \\
\hline $\mathrm{CH}_{2}=\mathrm{C}\left(\mathrm{CH}_{3}\right)-\mathrm{COOCH}_{3}$ & 0.74 & 0.4 \\
\hline $\mathrm{CH}_{2}=\mathrm{CH}-\mathrm{CN}$ & 0.60 & 1.2 \\
\hline
\end{tabular}

and perfluoroisopropenyl $\left(\mathrm{CF}_{2}=\mathrm{C}\left(\mathrm{CF}_{3}\right)_{-}\right)$derivatives are similarly low. Therefore, the addition polymerization reactivities of many fluorinated vinyl monomers have remained widely open, although those of hydrocarbon analogs are easily determined.

The anionic addition polymerization reactivity of fluorinated vinyl monomers should be high as these compounds would be good anion acceptors because of the high electron-withdrawing inductive effect of the fluorine substituents. ${ }^{2,3}$ The $e$-values of these monomers are generally larger than those of hydrocarbon analogs, as summarized in Table 1. Radical addition reactions of fluorinated vinyl monomers with cyclic ethers and alcohols have also been reported as these vinyl compounds are generally good radical acceptors. ${ }^{4}$ Therefore, facile carbon-carbon bond formation reactions could be achieved by anionic and radical additions of a wide variety of organic compounds to fluorinated vinyl compounds. These reactions could then be developed into the formation of carbon-carbon bonds from carbon-hydrogen bonds as functional groups in an aliphatic compound. It would also be possible to develop novel fluoropolymer syntheses by performing carbon-carbon bond formation reactions with difunctional compounds possessing two fluorinated vinyl groups.

\section{ANIONIC ADDITION POLYMERIZATION OF FLUORINATED VINYL MONOMERS}

As previously been reviewed, ${ }^{2,3}$ the anionic polymerization reactivity of acrylates and methacrylates possessing fluoroalkyl groups in ester moieties has been investigated since 1982, and the results have demonstrated that fluorine substituents have an extremely large effect on the reactivity of vinyl groups. For example, the anionic polymerization of hexafluoroisopropyl methacrylate $\left(\mathrm{CH}_{2}=\mathrm{C}\left(\mathrm{CH}_{3}\right)\right.$ $\left.\mathrm{COOCH}\left(\mathrm{CF}_{3}\right)_{2}\right)$ initiated by triethylaluminum produced the polymer in high yields, although methyl methacrylate had a low polymerization reactivity under similar reaction conditions because the initiation reactivity of organoaluminums is lower compared with that of organolithiums and organomagnesiums. Fluoroalkyl substituents that are linked four or five single bonds away from the vinyl groups have been shown to have a large effect on the reactivities of the vinyl groups of fluoroalkyl acrylates and methacrylates. The anionic polymerization of styrene derivatives possessing fluoro- or trifluoromethyl-substituted phenyl groups generally produces poor results. For example, $p$-trifluoromethylstyrene initiated by triethylaluminum in 1,2-dimethoxyethane produced a polymer in very low yield. These styrene derivatives therefore showed similar or slightly higher reactivities compared with those of hydrocarbon analogs, and corresponding homopolymers were obtained under traditional anionic polymerization conditions initiated by organolithiums or organomagnesiums.

Anionic polymerization has proven to be a reliable route for investigating the polymerization of fluorinated vinyl monomers because fluoroalkyl groups as ester moieties had a large effect on the anionic reactivity of vinyl groups of fluoroalkyl acrylates and methacrylates. However, the research approach only supplemented the field of traditional anionic polymerization by showing that traditional anionic polymerization was applicable to fluoroalkyl acrylates and methacrylates. The polymerization mentioned above provided no opportunity to open a new research field within anionic polymerization. Further work endeavored to challenge famous unsolved problems in the world of the fluorine chemistry, such as 2-trifluoromethylacrylates, $\alpha$-trifluoromethylstyrene, hexafluoro-1,3-butadiene, trifluorovinylbenzene and $\alpha$-trifluoromethylvinyl acetate, which were then reported to produce no corresponding homopolymers.

The radical homopolymerization of ethyl 2-trifluoromethylacrylate $\left(\mathrm{CH}_{2}=\mathrm{C}\left(\mathrm{CF}_{3}\right) \mathrm{COOC}_{2} \mathrm{H}_{5}\right)$ would be impossible under conventional radical conditions because the $e$-value of methyl 2-trifluoromethylacrylate is as high as 2.9 , as shown in Table 1 . Anionic polymerization could work well because of the high $e$-value. In 1985, anionic polymerization with initiators of relatively low reactivity, such as alkali metal tert-butoxide or organoaluminums, was examined to obtain high-molecular-weight polymers of ethyl 2-trifluoromethylacrylate in high yields. The incorporation of the trifluoromethyl group at the 2-position of acrylate is concluded to greatly enhance the anionic polymerization reactivity. The polymer yields of 2,2,2-trifluoroethyl 2-trifluoromethylacrylate $\left(\mathrm{CH}_{2}=\mathrm{C}\left(\mathrm{CF}_{3}\right) \mathrm{COOCH}_{2} \mathrm{CF}_{3}\right)$ and 1-trifluoromethyl-2,2,2-trifluoroethyl 2-trifluoromethylacrylate $\left(\mathrm{CH}_{2}=\mathrm{C}\left(\mathrm{CF}_{3}\right) \mathrm{COOCH}\left(\mathrm{CF}_{3}\right)_{2}\right)$ were lower than that of ethyl 2-trifluoromethylacrylate. These results indicated that the increase in trifluoromethyl substitution might have a greater influence on the reactivity of the propagating anion compared with the vinyl groups of 2-trifluoromethylacrylates. The reactivity of the propagating anion might be decreased because of the electron-withdrawing inductive effect of fluorine substituents.

Recently, 2-trifluoromethylacrylates possessing long alkyl groups in ester moieties, such as $\mathrm{CH}_{2}=\mathrm{C}\left(\mathrm{CF}_{3}\right) \mathrm{COOCH}\left(\mathrm{CF}_{3}\right) \mathrm{CF}_{2}\left(\mathrm{C}_{4} \mathrm{H}_{7} \mathrm{O}\right), \mathrm{CH}_{2}=$ $\mathrm{C}\left(\mathrm{CF}_{3}\right) \mathrm{COOCH}_{2} \mathrm{CH}\left(\mathrm{CF}_{3}\right) \mathrm{CH}_{2}\left(\mathrm{C}_{4} \mathrm{H}_{7} \mathrm{O}\right)$ and $\mathrm{CH}_{2}=\mathrm{C}\left(\mathrm{CF}_{3}\right) \mathrm{COOCH}_{2} \mathrm{CH}$ $\left(\mathrm{CF}_{3}\right) \mathrm{CH}_{2}\left(\mathrm{C}_{3} \mathrm{H}_{5} \mathrm{O}_{2}\right)$, were shown to yield corresponding homopolymers under the conventional radical conditions, although the yields are rather low as shown in Table 2. ${ }^{5}$ Fluoroalkyl groups in ester moieties were obtained from the radical addition of tetrahydrofuran or 1,3-dioxolane with 2-benzoxypentafluoropropene $\left(\mathrm{CF}_{2}=\mathrm{C}\left(\mathrm{CF}_{3}\right) \mathrm{OCOC}_{6} \mathrm{H}_{5}\right.$; BPFP) or tert-butyl 2-trifluoromethylacrylate, followed by hydrolysis, as mentioned below (see Scheme 7). This is an example of long-lived research serendipitously gaining new value.

No radical or anionic polymerization reaction has ever been reported for $\alpha$-trifluoromethylstyrene $\left(\mathrm{CH}_{2}=\mathrm{C}\left(\mathrm{CF}_{3}\right)-\mathrm{C}_{6} \mathrm{H}_{5}\right)$. A termination reaction may take place, as $\alpha$-trifluoromethylstyryl anion was not observed to react with other vinyl monomers in a study on anionic copolymerizations with hydrocarbon analogs. ${ }^{2,3}$ The inability of the $\alpha$-trifluoromethylstyryl anion to serve as a propagating living end may be due to the high electron-withdrawing effect of fluorine substituents or the abstraction of fluorine by a carbanion as a side reaction. The polymerization profile of $\alpha$-difluoromethylstyrene $\left(\mathrm{CH}_{2}=\mathrm{C}\left(\mathrm{CHF}_{2}\right)-\mathrm{C}_{6} \mathrm{H}_{5}\right)$ was found to be similar to that of $\alpha$-trifluoromethylstyrene. 
Table 2 Polymerization reactivity of 2-trifluoromethylacrylate

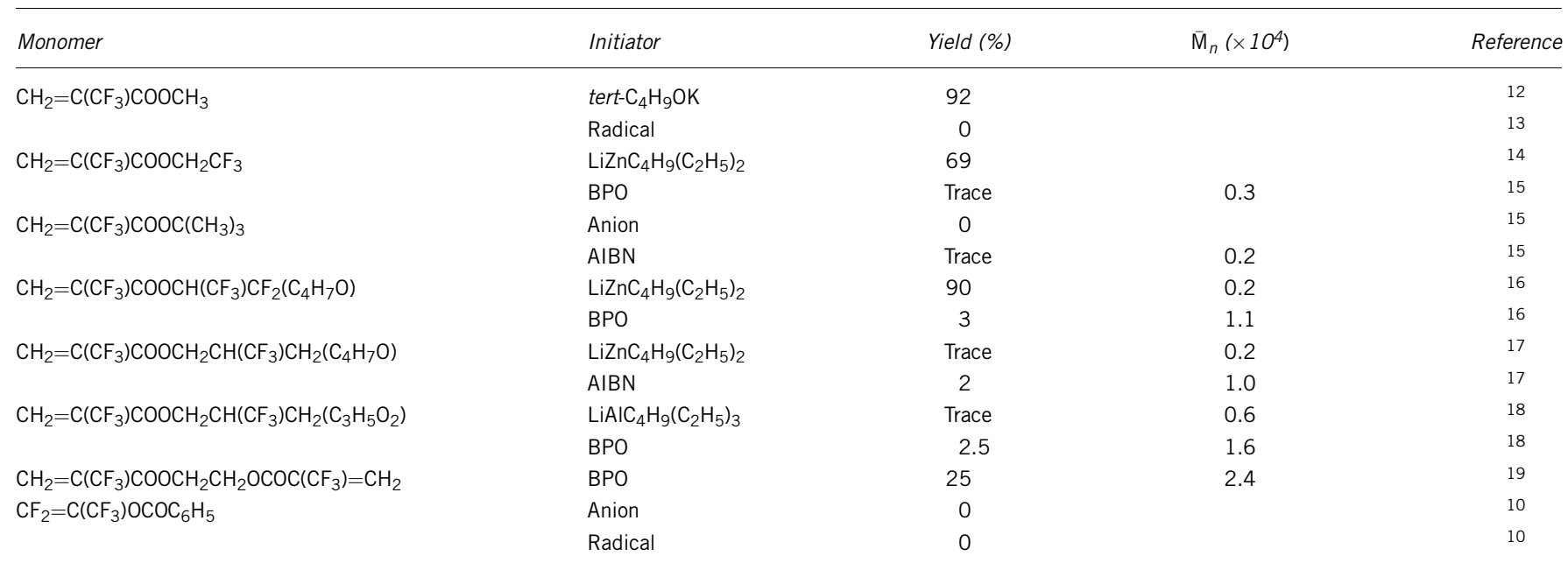

Abbreviations: AIBN, 2,2'-azobisisobutyronitrile; BPO, benzoyl peroxide.

Table 3 Anionic polymerization of hexafluoro-1,3-butadiene

\begin{tabular}{|c|c|c|c|c|}
\hline Initiator & Solvent & Temperature $\left({ }^{\circ} \mathrm{C}\right)$ & Time $(h)$ & Yield (\%) \\
\hline \multirow[t]{2}{*}{ CsF } & Toluene & 60 & 168 & 58.9 \\
\hline & THF & 60 & 168 & 71.6 \\
\hline \multirow[t]{2}{*}{$\mathrm{CsHCO}_{3}$} & Toluene & 60 & 168 & 0 \\
\hline & THF & 60 & 168 & 0 \\
\hline \multirow[t]{2}{*}{ tert- $\mathrm{C}_{4} \mathrm{H}_{9} \mathrm{Ocs}$} & Toluene & 60 & 3 & 83.9 \\
\hline & THF & 60 & 3 & 80.8 \\
\hline \multirow[t]{2}{*}{ tert- $\mathrm{C}_{4} \mathrm{H}_{9} \mathrm{OCs} / 18-C r o w n-6$} & Toluene & 60 & 3 & $31.2^{\mathrm{a}}$ \\
\hline & & 60 & 3 & $3.4^{b}$ \\
\hline \multirow[t]{2}{*}{$\mathrm{CH}_{3} \mathrm{COOCs}$} & Toluene & 60 & 168 & 0 \\
\hline & THF & 60 & 168 & 29.5 \\
\hline Cs naphthalene & THF & 60 & 3 & 74.3 \\
\hline $\mathrm{Cs}^{+}(\alpha-\mathrm{MeSt})_{n}{ }^{2-} \mathrm{Cs}^{+}$ & THF & 60 & 3 & 75.9 \\
\hline \multirow[t]{2}{*}{$\mathrm{C}_{2} \mathrm{H}_{5} \mathrm{Cs}$} & THF & 60 & 168 & 0 \\
\hline & Toluene & 60 & 168 & 0 \\
\hline
\end{tabular}

Abbreviation: THF, tetrahydrofuran.

atert- $\mathrm{C}_{4} \mathrm{H}_{9} \mathrm{OCs} / 18-C r o w n-6=1 / 1$.

${ }^{\mathrm{b}}$ tert- $\mathrm{C}_{4} \mathrm{H}_{9} \mathrm{OCs} / 18$-Crown- $6=1 / 2$

The polymerization of hexafluoro-1,3-butadiene has been studied under radical conditions since the 1960s and has been shown to produce viscous oily or grease-like oligomers in low yields. Highmolecular-weight polymers of hexafluoro-1,3-butadiene are produced under anionic conditions initiated with cesium fluoride, cesium tert-butoxide and organocesium compounds at a moderate temperature, as shown in Table 3. ${ }^{2,3}$ Poly(hexafluoro-1,3-butadiene) is partly soluble in hexafluorobenzene and insoluble in all other usual organic solvents. The structure of the polymer was found to be $-\left[\left(\mathrm{C}_{\left(\mathrm{CF}_{3}\right)}\right)=\right.$ $\left.\mathrm{C}\left(\mathrm{CF}_{3}\right)\right]_{n}-$ by ${ }^{13} \mathrm{C}$ nuclear magnetic resonance (NMR), X-ray photoelectron spectroscopy and solid-state Raman spectral measurements. These results prove the 2,3-addition structure. The isomerization reaction is then thought to occur during the polymerization as shown in Scheme 1.,3 It remains uncertain whether the reaction proceeds through hexafluoro-2-butyne because the isomerization of hexafluoro-1,3-butadiene to hexafluoro-2-butyne was reported to take place in the presence of an excess of cesium fluoride at $150{ }^{\circ} \mathrm{C}$, and the polymerization reaction conditions were far from those of the

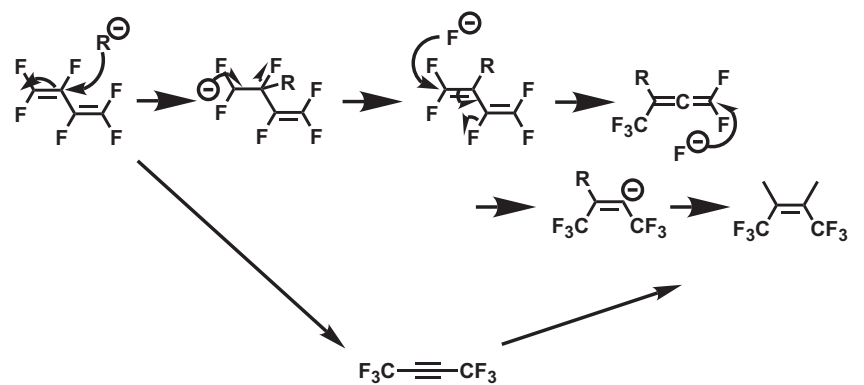

Scheme 1 Anionic polymerization mechanism of hexafluoro-1,3-butadiene.

isomerization of hexafluoro-1,3-butadiene, especially the reaction temperature. Insufficient research results have been obtained to determine the mechanism that would be preferable, as no report has been published on the reaction of anionic species with the 2-carbon of hexafluoro-1,3-butadiene.

The thermal expansion coefficient of the poly(hexafluoro-1, 3-butadiene) obtained in toluene is one-third of that of poly(tetrafluoroethylene) after heat treatment at $400{ }^{\circ} \mathrm{C}$ for $10 \mathrm{~h}$, and the thermostability increases significantly with the heat treatment, as shown in Figure 1. ${ }^{2}$ The thermal decomposition took place by random scission at about $650{ }^{\circ} \mathrm{C}$ because the products, $\mathrm{CF}_{2}, \mathrm{CF}_{3}$ and $\mathrm{CF}_{2} \mathrm{CF}_{3}$, were detected by mass spectrometry.

The addition polymerization reactivity of trifluorovinylbenzene is very low, and it has been reported to readily produce hexafluorocyclobutane derivatives under various reaction conditions. ${ }^{6}$ The anionic polymerization was conducted with several anionic initiators and was shown to afford homopolymers with the highest molecular weight of $1.9 \times 10^{4}$ with an extremely narrow molecular weight distribution and a low yield when initiated with cesium tert-butoxide and allowed to proceed at $60^{\circ} \mathrm{C}$ for $72 \mathrm{~h}$ in toluene. Poly(trifluorovinylbenzene) was produced by the initiation of diethyl(ethyl cyanoacetato)aluminum with $7 \%$ as the highest yield. No side reactions could take place once the polymerization reaction started because the molecular weight distribution was very narrow. ${ }^{2,3}$ A low initiator efficiency would fit the data, including the poor polymer yields. 


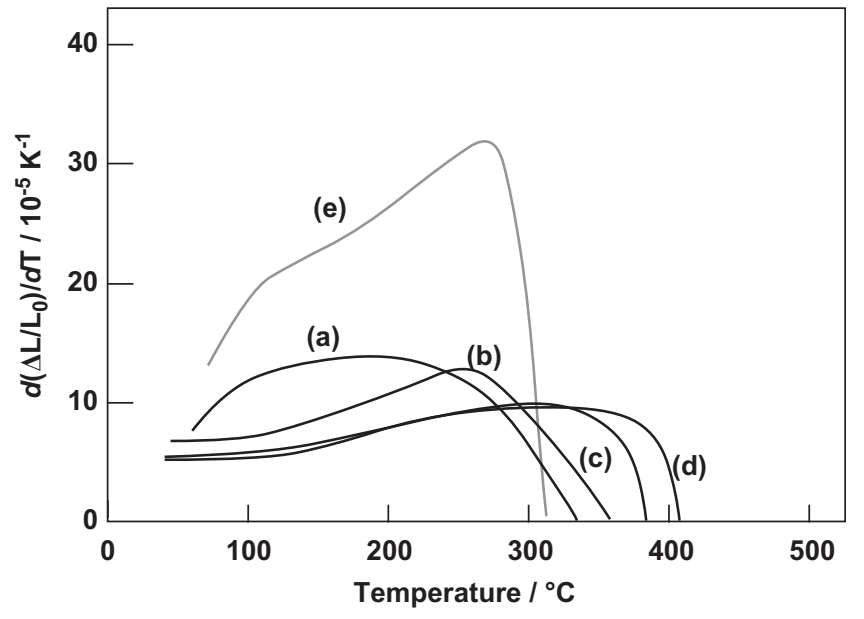

Figure 1 Temperature dependence of the thermal expansion coefficient of poly(hexafluoro-1,3-butadiene) after heat treatment: (a) none, (b) $200^{\circ} \mathrm{C}$ per $2 \mathrm{~h}$, (c) $400^{\circ} \mathrm{C}$ per $2 \mathrm{~h}$, (d) $400^{\circ} \mathrm{C}$ per $10 \mathrm{~h}$ and (e) poly(tetrafluoroethylene).

The polymerization of 1-trifluoromethylvinyl acetate $\left(\mathrm{CH}_{2}=\right.$ $\left.\mathrm{C}\left(\mathrm{CF}_{3}\right) \mathrm{OCOCH}_{3}\right)$ yielded polymers when initiated with Ziegler-type catalysts. $^{2}$

The methodology of anionic polymerization has proven an essential component of the investigation of the polymerization reactivities of fluorinated vinyl monomers. The anionic addition polymerization of fluorinated acrylates and methacrylates has revealed that these vinyl monomers have higher reactivities compared with hydrocarbon analogs, and that the corresponding homopolymers can be obtained by initiators of relatively low reactivities. The anionic addition polymerization was successful in the case of 2-trifluoromethylacrylates and hexafluoro-1,3-butadiene, which have never yielded high-molecularweight homopolymers under radical conditions. The incorporation of fluoroalkyl groups generally decreased the polymerization reactivity based on the yields of polymers of fluoroalkyl 2-trifluoromethylacrylates. The 2,3-addition polymerization of hexafluoro-1,3-butadiene was proven to take place, although no report has ever been published on 1,2- or 1,4-addition polymerization of hexafluoro-1,3-butadiene. The polymerization of hexafluoro-1,3-butadiene by the 1,2- or 1,4addition mechanism might hardly take place because hexafluoro-1, 3-butadiene is not a conjugated diene. ${ }^{7}$ The results of the polymerizations of 2-trifluoromethylacrylates and hexafluoro-1,3-butadiene might provide an avenue for a new field to be opened in anionic polymerization methodology. The results show that the anionic polymerization has not yet worked well for $\alpha$-trifluoromethylstyrene, $\alpha$-difluoromethylstyrene or trifluorovinylbenzene. The tacticity of poly(ethyl 2-trifluoromethylacrylate) has not yet been studied by ${ }^{19} \mathrm{~F}$ NMR measurement, which might afford more information than ${ }^{1} \mathrm{H}$ and ${ }^{13} \mathrm{C}$ NMR because of the ability to detect long-range interactions of fluorine atoms. The investigation on the reactivity of fluorinated vinyl monomers should be a high priority for the field of anionic polymerization methodology from the academic point of view.

\section{INITIATION REACTIVITY OF ANIONIC POLYMERIZATION OF FLUORINATED ACRYLATES}

The anionic polymerization reactivities of fluorinated acrylates and methacrylates are becoming clearer, as demonstrated in the previous section; therefore, a logical next step would be to quantitatively establish the order of reactivity of several fluorinated vinyl monomers under anionic conditions. ${ }^{5,8}$ Pseudo first-order rate constants, $k^{\prime}$, of the reaction of diethyl(ethyl cyanoacetato)aluminum $\left(\left(\mathrm{C}_{2} \mathrm{H}_{5}\right)_{2}\right.$ $\mathrm{Al}\left(\mathrm{NCCHCOOC} \mathrm{H}_{5} ; \mathrm{Et}_{2} \mathrm{AlECA}\right)$ in the presence of large excess amounts of fluorinated acrylates and methacrylates might allow for quantitative comparisons of reactivity, as $\mathrm{Et}_{2} \mathrm{AlECA}$ showed moderate polymerization reactivity toward these monomers. The reactions should be simple, as the Michael addition would take place without any other side reactions such as carbonyl addition or hydrogen abstraction reactions, which likely take place in typical anionic polymerizations of hydrocarbon analogs initiated by organolithiums and organomagnesiums. The reaction system would therefore be an appropriate model to investigate the initiation reaction in the anionic polymerization of fluorinated vinyl monomers. The results are summarized in Table $4 .^{5,8}$

The reactivity order is as follows: $\mathrm{CH}_{2}=\mathrm{C}\left(\mathrm{CF}_{3}\right) \mathrm{COOC}_{2} \mathrm{H}_{5}>$ $\mathrm{CH}_{2}=\mathrm{C}\left(\mathrm{CF}_{3}\right) \mathrm{COOCH}\left(\mathrm{CH}_{3}\right)_{2}>\mathrm{CH}_{2}=\mathrm{CHCOOCH}_{2} \mathrm{C}_{6} \mathrm{~F}_{5}>\mathrm{CH}_{2}=\mathrm{C}\left(\mathrm{CF}_{3}\right)$ $\mathrm{COOC}\left(\mathrm{CH}_{3}\right)_{3}>\mathrm{CH}_{2}=\mathrm{C}\left(\mathrm{CF}_{3}\right) \mathrm{COOCH}_{2} \mathrm{C}_{6} \mathrm{~F}_{5}>\mathrm{CH}_{2}=\mathrm{C}\left(\mathrm{CF}_{3}\right) \mathrm{COOCH}$ $\left(\mathrm{CF}_{3}\right)_{2} \geqslant \mathrm{CH}_{2}=\mathrm{CHCOOCH}_{3}>\mathrm{CH}_{2}=\mathrm{CHCOOCH}_{2} \mathrm{C}_{6} \mathrm{H}_{5} \geqslant \mathrm{CH}_{2}=\mathrm{C}\left(\mathrm{CF}_{3}\right)$ $\mathrm{COOCH}_{2} \mathrm{CF}_{3}>\mathrm{CH}_{2}=\mathrm{CHCOOCH}_{2} \mathrm{CH}_{2} \mathrm{C}_{8} \mathrm{~F}_{17}>\mathrm{CH}_{2}=\mathrm{C}\left(\mathrm{CH}_{3}\right) \mathrm{COOCH}_{2}$ $\mathrm{C}_{6} \mathrm{~F}_{5}>\mathrm{CH}_{2}=\mathrm{CHCOOCH}_{2} \mathrm{CF}_{3}>\mathrm{CH}_{2}=\mathrm{CHCOOCH}_{2} \mathrm{C}_{2} \mathrm{~F}_{5}>\mathrm{CH}_{2}=$ $\mathrm{CHCOOCH}\left(\mathrm{CF}_{3}\right)_{2}>\mathrm{CH}_{2}=\mathrm{C}\left(\mathrm{CH}_{3}\right) \mathrm{COOCH}_{3} \geqslant \mathrm{CH}_{2}=\mathrm{C}\left(\mathrm{CH}_{3}\right) \mathrm{COOCH}_{2}$ $\mathrm{C}_{6} \mathrm{H}_{5} \geqslant \mathrm{CH}_{2}=\mathrm{C}\left(\mathrm{CH}_{3}\right) \mathrm{COOCH}_{2} \mathrm{CH}_{2} \mathrm{C}_{8} \mathrm{~F}_{17}>\mathrm{CH}_{2}=\mathrm{C}\left(\mathrm{CH}_{3}\right) \mathrm{COOCH}$ $\left(\mathrm{CH}_{3}\right)_{2}>\mathrm{CH}_{2}=\mathrm{C}\left(\mathrm{CH}_{3}\right) \mathrm{COOCH}_{2} \mathrm{C}_{2} \mathrm{~F}_{5} \geqslant \mathrm{CH}_{2}=\mathrm{C}\left(\mathrm{CH}_{3}\right) \mathrm{COOCH}_{2} \mathrm{CF}_{3}$.

The order of reactivity seems to be complicated, with no regular pattern observed among the 18 fluorinated acrylates and methacrylates.

The reactivity of 2-trifluoromethylacrylates is greater than that of the acrylates, and the reactivity of methacrylates is the lowest because the order of rate constants is $\mathrm{CH}_{2}=\mathrm{C}\left(\mathrm{CF}_{3}\right) \mathrm{COOC}_{2} \mathrm{H}_{5}>$ $\mathrm{CH}_{2}=\mathrm{CHCOOCH}_{3}>\mathrm{CH}_{2}=\mathrm{C}\left(\mathrm{CH}_{3}\right) \mathrm{COOCH}_{3}$ and $\mathrm{CH}_{2}=\mathrm{C}\left(\mathrm{CF}_{3}\right)$ $\mathrm{COOCH}_{2} \mathrm{CF}_{3}>\mathrm{CH}_{2}=\mathrm{CHCOOCH}_{2} \mathrm{CF}_{3}>\mathrm{CH}_{2}=\mathrm{C}\left(\mathrm{CH}_{3}\right) \mathrm{COOCH}_{2} \mathrm{CF}_{3}$. This demonstrates that the introduction of the trifluoromethyl group at the $\alpha$-position enhances the reactivity of the vinyl group toward anionic species. The order may be consistent with the fact that the anionic polymerization of $\mathrm{CH}_{2}=\mathrm{C}\left(\mathrm{CF}_{3}\right) \mathrm{COOC}_{2} \mathrm{H}_{5}$ and $\mathrm{CH}_{2}=\mathrm{CHCOOCH}_{3}$ readily takes place upon initiation with organoaluminums, whereas $\mathrm{CH}_{2}=\mathrm{C}\left(\mathrm{CH}_{3}\right) \mathrm{COOCH}_{3}$ shows very low polymerization reactivity under similar conditions.

The reactivity orders of 2-trifluoromethylacrylates, methacrylates and acrylates can be summarized, respectively, as follows:

$\mathrm{CH}_{2}=\mathrm{C}\left(\mathrm{CF}_{3}\right) \mathrm{COOC}_{2} \mathrm{H}_{5}>\mathrm{CH}_{2}=\mathrm{C}\left(\mathrm{CF}_{3}\right) \mathrm{COOCH}\left(\mathrm{CH}_{3}\right)_{2}>\mathrm{CH}_{2}=$ $\mathrm{C}\left(\mathrm{CF}_{3}\right) \mathrm{COOC}\left(\mathrm{CH}_{3}\right)_{3}>\mathrm{CH}_{2}=\mathrm{C}\left(\mathrm{CF}_{3}\right) \mathrm{COOCH}_{2} \mathrm{C}_{6} \mathrm{~F}_{5}>\mathrm{CH}_{2}=\mathrm{C}\left(\mathrm{CF}_{3}\right)$ $\mathrm{COOCH}\left(\mathrm{CF}_{3}\right)_{2}>\mathrm{CH}_{2}=\mathrm{C}\left(\mathrm{CF}_{3}\right) \mathrm{COOCH}_{2} \mathrm{CF}_{3}$.

$\mathrm{CH}_{2}=\mathrm{C}\left(\mathrm{CH}_{3}\right) \mathrm{COOCH}_{2} \mathrm{C}_{6} \mathrm{~F}_{5}>\mathrm{CH}_{2}=\mathrm{C}\left(\mathrm{CH}_{3}\right) \mathrm{COOCH}_{3} \geqslant \mathrm{CH}_{2}=\mathrm{C}\left(\mathrm{CH}_{3}\right)$ $\mathrm{COOCH}_{2} \mathrm{C}_{6} \mathrm{H}_{5} \geqslant \mathrm{CH}_{2}=\mathrm{C}\left(\mathrm{CH}_{3}\right) \mathrm{COOCH}_{2} \mathrm{CH}_{2} \mathrm{C}_{8} \mathrm{~F}_{17}>\mathrm{CH}_{2}=\mathrm{C}\left(\mathrm{CH}_{3}\right)$ $\mathrm{COOCH}\left(\mathrm{CH}_{3}\right)_{2}>\mathrm{CH}_{2}=\mathrm{C}\left(\mathrm{CH}_{3}\right) \mathrm{COOCH}_{2} \mathrm{C}_{2} \mathrm{~F}_{5} \geqslant \mathrm{CH}_{2}=\mathrm{C}\left(\mathrm{CH}_{3}\right) \mathrm{COOCH}_{2} \mathrm{CF}_{3}$. $\mathrm{CH}_{2}=\mathrm{CHCOOCH}_{2} \mathrm{C}_{6} \mathrm{~F}_{5}>\mathrm{CH}_{2}=\mathrm{CHCOOCH}_{3}>\mathrm{CH}_{2}=\mathrm{CHCOOCH}_{2}$ $\mathrm{C}_{6} \mathrm{H}_{5}>\mathrm{CH}_{2}=\mathrm{CHCOOCH}_{2} \mathrm{CH}_{2} \mathrm{C}_{8} \mathrm{~F}_{17}>\mathrm{CH}_{2}=\mathrm{CHCOOCH}_{2} \mathrm{CF}_{3}>\mathrm{CH}_{2}=$ $\mathrm{CHCOOCH}_{2} \mathrm{C}_{2} \mathrm{~F}_{5}>\mathrm{CH}_{2}=\mathrm{CHCOOCH}\left(\mathrm{CF}_{3}\right)_{2}$.

The reactivity of $\mathrm{CH}_{2}=\mathrm{C}\left(\mathrm{CF}_{3}\right) \mathrm{COOC}_{2} \mathrm{H}_{5}$ is higher than that of $\mathrm{CH}_{2}=\mathrm{C}\left(\mathrm{CF}_{3}\right) \mathrm{COOCH}_{2} \mathrm{CF}_{3}$, and the order of reactivity is similar to the order of polymer yields. The result indicates that one more trifluoromethyl substitution decreases the reactivity toward the carbanion, even though the trifluoromethyl group is linked four single bonds away from the vinyl group. Similar results are observed in the case of 2-trifluoromethylacrylates and acrylates, with orders of $\mathrm{CH}_{2}=\mathrm{C}\left(\mathrm{CF}_{3}\right) \mathrm{COOCH}\left(\mathrm{CH}_{3}\right)_{2}>\mathrm{CH}_{2}=\mathrm{C}\left(\mathrm{CF}_{3}\right) \mathrm{COOCH}\left(\mathrm{CF}_{3}\right)_{2}$ and $\mathrm{CH}_{2}=$ $\mathrm{CHCOOCH}_{3}>\mathrm{CH}_{2}=\mathrm{CHCOOCH}_{2} \mathrm{CF}_{3}>\mathrm{CH}_{2}=\mathrm{CHCOOCH}_{2} \mathrm{C}_{2} \mathrm{~F}_{5}>$ $\mathrm{CH}_{2}=\mathrm{CHCOOCH}\left(\mathrm{CF}_{3}\right)_{2}$, respectively. The order of $\mathrm{CH}_{2}=\mathrm{C}\left(\mathrm{CH}_{3}\right)$ $\mathrm{COOCH}_{3}>\mathrm{CH}_{2}=\mathrm{C}\left(\mathrm{CH}_{3}\right) \mathrm{COOCH}_{2} \mathrm{CF}_{3}$ is inconsistent with that of 
Table 4 Relationship between log $K$ of fluorinated acrylates and methacrylates with diethyl(ethyl cyanoacetato)aluminum and spectroscopic data

\begin{tabular}{|c|c|c|c|c|c|c|c|}
\hline Run & Monomer & Temperature $\left({ }^{\circ} \mathrm{C}\right)$ & $5+\log k^{\prime}$ & e-Value & $\beta$-Carbon (p.p.m.) ${ }^{a}$ & $C=O(p . p . m .)^{a}$ & $C=O\left(\mathrm{~cm}^{-1}\right)^{\mathrm{b}}$ \\
\hline 1 & $\mathrm{CH}_{2}=\mathrm{C}\left(\mathrm{CH}_{3}\right) \mathrm{COOCH}_{3}$ & 40 & 0.81 & 0.4 & 125.3 & 167.9 & 1732 \\
\hline 2 & $\mathrm{CH}_{2}=\mathrm{C}\left(\mathrm{CH}_{3}\right) \mathrm{COOCH}\left(\mathrm{CH}_{3}\right)_{2}$ & 40 & 0.40 & 0.10 & 124.8 & 166.9 & 1718 \\
\hline 3 & $\mathrm{CH}_{2}=\mathrm{C}\left(\mathrm{CH}_{3}\right) \mathrm{COOCH}_{2} \mathrm{C}_{6} \mathrm{H}_{5}$ & 40 & 0.68 & 0.42 & 125.7 & 167.1 & 1716 \\
\hline 4 & $\mathrm{CH}_{2}=\mathrm{C}\left(\mathrm{CH}_{3}\right) \mathrm{COOCH}_{2} \mathrm{CF}_{3}$ & 40 & -0.05 & 0.98 & 127.7 & 165.6 & 1738 \\
\hline 5 & $\mathrm{CH}_{2}=\mathrm{C}\left(\mathrm{CH}_{3}\right) \mathrm{COOCH}_{2} \mathrm{C}_{2} \mathrm{~F}_{5}$ & 40 & 0.00 & - & 127.8 & 165.5 & 1743 \\
\hline 6 & $\mathrm{CH}_{2}=\mathrm{C}\left(\mathrm{CH}_{3}\right) \mathrm{COOCH}_{2} \mathrm{C}_{6} \mathrm{~F}_{5}$ & 40 & 1.56 & 0.48 & 126.5 & 166.5 & 1727 \\
\hline 7 & $\mathrm{CH}_{2}=\mathrm{C}\left(\mathrm{CH}_{3}\right) \mathrm{COOCH}\left(\mathrm{CF}_{3}\right)_{2}$ & 0 & - & - & 129.7 & 163.9 & 1758 \\
\hline 8 & $\mathrm{CH}_{2}=\mathrm{C}\left(\mathrm{CH}_{3}\right) \mathrm{COOCH}_{2} \mathrm{CH}_{2} \mathrm{C}_{8} \mathrm{~F}_{17}$ & 40 & 0.53 & - & 126.3 & 166.9 & 1728 \\
\hline 9 & $\mathrm{CH}_{2}=\mathrm{C}\left(\mathrm{CF}_{3}\right) \mathrm{COOCH}_{2} \mathrm{CH}_{3}$ & 0 & 1.69 & 2.9 & 132.5 & 161.3 & 1740 \\
\hline 10 & $\mathrm{CH}_{2}=\mathrm{C}\left(\mathrm{CF}_{3}\right) \mathrm{COOCH}\left(\mathrm{CH}_{3}\right)_{2}$ & 0 & 1.59 & - & 132.1 & 160.7 & 1736 \\
\hline 11 & $\mathrm{CH}_{2}=\mathrm{C}\left(\mathrm{CF}_{3}\right) \mathrm{COOC}\left(\mathrm{CH}_{3}\right)_{3}$ & 0 & 1.39 & - & 131.6 & 160.4 & 1736 \\
\hline 12 & $\mathrm{CH}_{2}=\mathrm{C}\left(\mathrm{CF}_{3}\right) \mathrm{COOCH}_{2} \mathrm{CF}_{3}$ & 0 & 0.62 & - & 134.7 & 159.6 & 1760 \\
\hline 13 & & 40 & 1.87 & - & 134.7 & 159.6 & 1760 \\
\hline 14 & $\mathrm{CH}_{2}=\mathrm{C}\left(\mathrm{CF}_{3}\right) \mathrm{COOCH}_{2} \mathrm{C}_{6} \mathrm{~F}_{5}$ & 0 & 1.35 & - & 133.9 & 160.6 & 1747 \\
\hline 15 & $\mathrm{CH}_{2}=\mathrm{C}\left(\mathrm{CF}_{3}\right) \mathrm{COOCH}\left(\mathrm{CF}_{3}\right)_{2}$ & 0 & 1.26 & - & 136.4 & 158.1 & 1776 \\
\hline 16 & & 40 & 1.71 & - & 136.4 & 158.1 & 1776 \\
\hline 17 & $\mathrm{CH}_{2}=\mathrm{CHCOOCH}_{3}$ & 0 & 0.84 & 0.6 & 130.6 & 166.6 & 1731 \\
\hline $18^{\mathrm{c}}$ & & 40 & 1.89 & 0.6 & 130.6 & 166.6 & 1731 \\
\hline 19 & $\mathrm{CH}_{2}=\mathrm{CHCOOCH}_{2} \mathrm{C}_{6} \mathrm{H}_{5}$ & 0 & 0.68 & 1.13 & 131.0 & 165.9 & 1726 \\
\hline 20 & $\mathrm{CH}_{2}=\mathrm{CHCOOCH}_{2} \mathrm{CF}_{3}$ & 0 & -0.05 & 1.13 & 133.0 & 164.4 & 1762 \\
\hline 21 & & 40 & 1.47 & 1.13 & 133.0 & 164.4 & 1762 \\
\hline 22 & $\mathrm{CH}_{2}=\mathrm{CHCOOCH}_{2} \mathrm{C}_{2} \mathrm{~F}_{5}$ & 40 & 1.31 & - & 133.2 & 164.3 & 1751 \\
\hline 23 & $\mathrm{CH}_{2}=\mathrm{CHCOOCH}_{2} \mathrm{C}_{6} \mathrm{~F}_{5}$ & 0 & 1.48 & - & 131.9 & 165.2 & 1736 \\
\hline 24 & $\mathrm{CH}_{2}=\mathrm{CHCOOCH}\left(\mathrm{CF}_{3}\right)_{2}$ & 40 & 1.14 & 1.36 & 135.3 & 162.6 & 1763 \\
\hline 25 & $\mathrm{CH}_{2}=\mathrm{CHCOOCH}_{2} \mathrm{CH}_{2} \mathrm{C}_{8} \mathrm{~F}_{17}$ & 40 & 1.74 & - & 131.5 & 165.6 & 1736 \\
\hline 26 & $\mathrm{CH}_{2}=\mathrm{CFCOOC}\left(\mathrm{CH}_{3}\right)_{3}$ & 40 & - & - & 101.4 & 159.4 & 1739 \\
\hline 27 & $\mathrm{CH}_{2}=\mathrm{CFCOOCH} \mathrm{C}_{2} \mathrm{~F}_{5}$ & 40 & - & - & 104.8 & 158.7 & 1767 \\
\hline
\end{tabular}

a Determined by ${ }^{13} \mathrm{C}$ nuclear magnetic resonance in $\mathrm{CDCl}_{3}$.

betermined by infrared.

'Toluene: $15 \mathrm{ml}$.

the polymerization reactivity based on the polymer yields for organoaluminum initiation. The initiation reactivity of $\mathrm{CH}_{2}=\mathrm{C}\left(\mathrm{CF}_{3}\right)$ $\operatorname{COOCH}\left(\mathrm{CH}_{3}\right)_{2}$ is higher than that of $\mathrm{CH}_{2}=\mathrm{C}\left(\mathrm{CF}_{3}\right) \mathrm{COOC}\left(\mathrm{CH}_{3}\right)_{3}$, probably because of the bulkiness of the substituents. A similar order is observed for $\mathrm{CH}_{2}=\mathrm{C}\left(\mathrm{CH}_{3}\right) \mathrm{COOCH}_{3}>\mathrm{CH}_{2}=\mathrm{C}\left(\mathrm{CH}_{3}\right) \mathrm{COOCH}$ $\left(\mathrm{CH}_{3}\right)_{2}$, probably because of the same reason. The effect of the pentafluorophenylmethyl group as the ester moiety seems to be different from that of other fluoroalkyl groups because the reactivity order is $\mathrm{CH}_{2}=\mathrm{CHCOOCH}_{2} \mathrm{C}_{6} \mathrm{~F}_{5}>\mathrm{CH}_{2}=\mathrm{C}\left(\mathrm{CF}_{3}\right) \mathrm{COOCH}_{2} \mathrm{C}_{6} \mathrm{~F}_{5}>\mathrm{CH}_{2}=$ $\mathrm{C}\left(\mathrm{CH}_{3}\right) \mathrm{COOCH}_{2} \mathrm{C}_{6} \mathrm{~F}_{5}$. The effect of the pentafluorophenyl group in pentafluorostyrene $\left(\mathrm{CH}_{2}=\mathrm{CH}-\mathrm{C}_{6} \mathrm{~F}_{5}\right)$ could, however, scarcely be demonstrated because no polymer was obtained with organoaluminum initiation. These findings prove the limited effect of the pentafluorophenyl group on the reactivity of the vinyl group, with a modest increase in the reactivity to anionic species observed. The effect of the pentafluorophenylmethyl group was therefore different from that of the pentafluorophenyl group.

Table 4 also presents spectroscopic characteristics such as the ${ }^{13} \mathrm{C}$ NMR chemical shifts of $\beta$-carbons and carbonyl carbons and the infrared absorptions of carbonyl groups of the monomers. Figure 2 shows the relationship between $\log k^{\prime}$ and the ${ }^{13} \mathrm{C}$ NMR chemical shifts of the $\beta$-carbons of fluorinated acrylates and methacrylates. ${ }^{5,8} \mathrm{~A}$ linear relationship is observed between $\log k^{\prime}$ and the chemical shifts of fluoroalkyl acrylates $(18,21,22,24$ and 25) in Figure 2a. The results are in accordance with the decrease in reactivity upon increasing the number of trifluoromethyl groups. A poor dependence is observed in the case of 2-trifluoromethylacrylates $(9,10,11,12,14$ and 15) and methacrylates $(1,2,3,4,5,6$ and 8). A linear relationship is observed for 2,2,2-trifluoroethyl esters, such as $\mathrm{CH}_{2}=\mathrm{C}\left(\mathrm{CH}_{3}\right) \mathrm{COOCH}_{2} \mathrm{CF}_{3}$, $\mathrm{CH}_{2}=\mathrm{C}\left(\mathrm{CF}_{3}\right) \mathrm{COOCH}_{2} \mathrm{CF}_{3}$ and $\mathrm{CH}_{2}=\mathrm{CHCOOCH}_{2} \mathrm{CF}_{3}$ (4, 13 and 21).

Figure 3 summarizes the relationship between $\log k^{\prime}$ and the ${ }^{13} \mathrm{C}$ NMR chemical shifts of carbonyl carbons. ${ }^{5,8}$ A linear relationship is observed between $\log k^{\prime}$ and the chemical shifts of acrylates $(18,21,22$ and 24) and methacrylates (1, 2, 3, 4, 5, 6 and 8) in Figure 3a, and some dependence is shown in Figure $3 \mathrm{~b}$ in the case of 2-trifluoromethylacrylates $(9,10,11,12,14$ and 15) and acrylates (17, 19 and 20). The results could be used to estimate the reactivities of 2-trifluoromethylacrylate, acrylates and methacrylates, respectively, by comparing the ${ }^{13} \mathrm{C}$ NMR chemical shifts of their carbonyl carbons with those of other fluorinated acrylates and methacrylates.

No obvious relationship was observed between $\log k^{\prime}$ and the infrared wave numbers of carbonyl groups, although the $e$-values of acrylates and methacrylates, including fluorinated ones, were found to be proportional to wave numbers of carbonyl groups, as previously reported. $2,5,8$

No rate constants were obtained for $\mathrm{CH}_{2}=\mathrm{C}\left(\mathrm{CH}_{3}\right) \mathrm{COOCH}\left(\mathrm{CF}_{3}\right)_{2}$, $\mathrm{CH}_{2}=\mathrm{CFCOOC}\left(\mathrm{CH}_{3}\right)_{3}$ or $\mathrm{CH}_{2}=\mathrm{CFCOOCH}_{2} \mathrm{C}_{2} \mathrm{~F}_{5}$ because the polymerizations took place too rapidly, and the reaction system did not maintain a large excess amount of a monomer. The pseudo first-order rate constants of $\mathrm{CH}_{2}=\mathrm{CFCOOC}\left(\mathrm{CH}_{3}\right)_{3}$ and $\mathrm{CH}_{2}=\mathrm{CFCOOCH} \mathrm{C}_{2} \mathrm{~F}_{5}$ are presumed to be extremely different from those of fluoroalkyl acrylates because the chemical shifts of the $\beta$-carbons of these mono- 

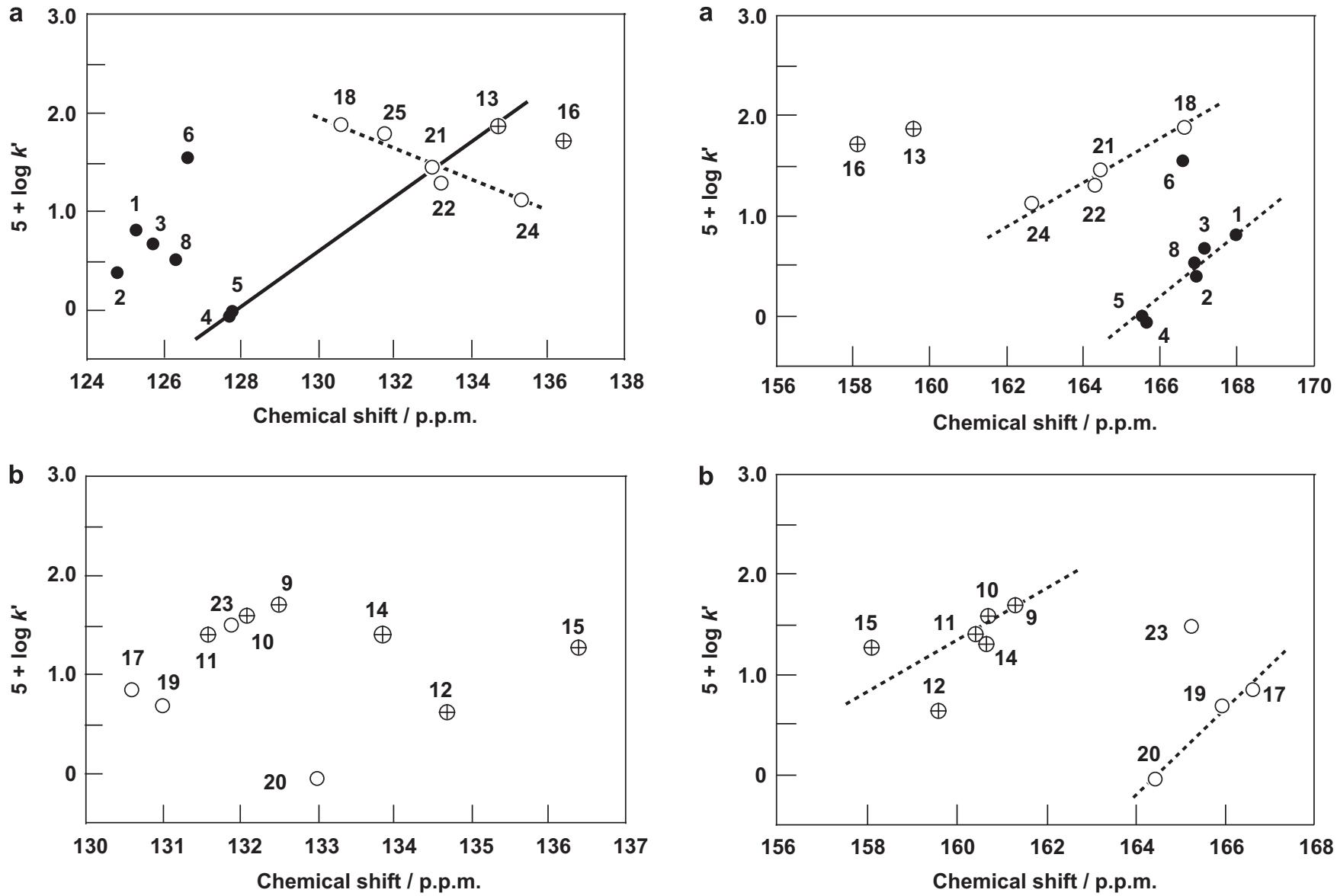

Figure $2 \log K$ at $40{ }^{\circ} \mathrm{C}$ (a) and at $0{ }^{\circ} \mathrm{C}$ (b) vs ${ }^{13} \mathrm{C}$ NMR chemical shifts of $\beta$-carbons of fluorinated acrylates and methacrylates (refer to Table 4): $(\oplus)$ 2-trifluoromethylacrylate; $(\bullet)$ methacrylate; $(\bigcirc)$ acrylate.

mers are 101.4 and 104.8 p.p.m., respectively, considerably smaller than those of other fluorinated acrylates.

In conclusion, the order of reactivity of fluorinated acrylates and methacrylates toward anionic species was demonstrated by measuring pseudo first-order rate constants. The high anionic addition reactivity was exhibited by introducing a trifluoromethyl group into the vinyl group at the $\alpha$-position, and introducing a fluoroalkyl group in the ester moiety of 2-trifluoromethylacrylates decreased their reactivities toward the anionic species. The result is in agreement with that based on the polymer yields. The initiation reactivity was generally decreased by introducing fluoroalkyl groups into ester moieties of acrylate and methacrylate derivatives. The results are roughly consistent with those based on the polymer yields of fluoroalkyl acrylates and methacrylates. A linear relationship was observed between pseudo first-order rate constants and the ${ }^{13} \mathrm{C}$ NMR chemical shifts of the carbonyl carbons of 2-trifluoromethylacrylates, methacrylates and acrylates. A limited relationship was observed between the rate constants and ${ }^{13} \mathrm{C} N M R$ chemical shifts of $\beta$-carbons. No relationship was observed between the rate constants and infrared absorptions of carbonyl groups, respectively. The bulkiness of the fluoroalkyl groups exerted a minor effect on the reactivity. A theoretical study should be conducted based on the results shown in Table 4, because the order of reactivity as determined by the pseudo first-order rate constants seems to be complicated and lacking in a regular pattern. A quantitative investigation must also be carried out on the propagation reaction to clarify the
Figure 3 Log $K$ at $40{ }^{\circ} \mathrm{C}$ (a) and at $0{ }^{\circ} \mathrm{C}$ (b) vs ${ }^{13} \mathrm{C}$ NMR chemical shifts of carbonyl carbons of fluorinated acrylates and methacrylates (refer to Table 4): $(\oplus)$ 2-trifluoromethylacrylate; $(\bullet)$ methacrylate; $(O)$ acrylate.

overall polymerization reactivity of fluorinated acrylates and methacrylates. The rate constants were related to a certain extent to the polymerization reactivity based on polymer yields, with higher polymer yields obtained from the organoaluminum-initiated anionic polymerization of fluoroalkyl acrylates and methacrylates, such as $\mathrm{CH}_{2}=\mathrm{C}\left(\mathrm{CH}_{3}\right) \mathrm{COOCH}\left(\mathrm{CF}_{3}\right)_{2}, \mathrm{CH}_{2}=\mathrm{CHCOOCH}_{2} \mathrm{CF}_{3}$ and $\mathrm{CH}_{2}=$ $\mathrm{C}\left(\mathrm{CH}_{3}\right) \mathrm{COOCH}_{2} \mathrm{CF}_{3}$. It is also desirable to calculate the order of reactivity according to theoretical chemistry to determine the factors that exert the most control over the whole polymerization reaction to gain a quantitative understanding of the polymerization reactivity. The investigation on the anionic polymerization is at its beginning, and the broad research field must also remain open for theoretical work.

\section{ANIONIC POLYADDITION OF 2-TRIFLUOROMETHYLACRYLATE}

The Michael addition reaction of active methylene compounds such as acetylacetone, alkyl acetoacetate, dialkyl malonate, alkyl cyanoacetate and malononitrile is a well-known reaction in organic chemistry textbooks that takes place in an anionic manner in order to form carbon-carbon bonds with vinyl compounds such as acrylonitrile, acrylates and vinyl ketones. Double Michael addition reactions have been reported to take place for the reactions of vinyl compounds such as acrylonitrile and methyl vinyl ketone with diethyl malonate and ethyl cyanoacetate (ECA) to afford the corresponding di-addition products of active methylene compounds in high 
Table 5 Double Michael polyaddition of 1,4-phenylene bis(2-trifluoromethylacrylate) with ethyl cyanoacetate

\begin{tabular}{|c|c|c|c|c|c|c|c|c|c|}
\hline Run & $E C A(m m o l)$ & Solvent & & Base (mmol) & Temperature $\left({ }^{\circ} \mathrm{C}\right)$ & Time (day) & Yield (\%) & $\overline{\mathrm{M}}_{n}\left(\times 10^{4}\right)^{\mathrm{a}}$ & $\overline{\mathrm{M}}_{w} / \overline{\mathrm{M}}_{n}^{\mathrm{a}}$ \\
\hline 2 & 2.5 & & & 0.25 & 60 & 1 & 39.4 & 0.64 & 1.7 \\
\hline 4 & 5.0 & & & 0.25 & 60 & 1 & 52.7 & 0.84 & 2.7 \\
\hline 5 & 5.0 & & & 0.5 & 60 & 1 & 21.0 & $1.2^{\mathrm{b}}$ & $2.9^{b}$ \\
\hline 6 & 12.5 & & & 0.25 & 60 & 1 & 52.7 & 1.0 & 2.4 \\
\hline 9 & 25.0 & & & 0.25 & 60 & 1 & 73.0 & 0.98 & 2.5 \\
\hline 10 & 25.0 & & & 0.25 & 60 & 1 & 61.6 & 0.83 & 1.8 \\
\hline 11 & 25.0 & & & 0.25 & Rt & 1 & Gel & $1.1^{\mathrm{b}}$ & $4.8^{b}$ \\
\hline 12 & 25.0 & & & 0.5 & 60 & 1 & 67.8 & 0.89 & 2.1 \\
\hline 13 & 25.0 & & & 0.5 & 60 & 1 & 35.8 & 0.46 & 2.1 \\
\hline 14 & 25.0 & & & 0.5 & 60 & 2 & 31.9 & 0.56 & 1.7 \\
\hline
\end{tabular}

Abbreviations: ECA, ethyl cyanoacetate; Rt, room temperature.

1,4-Phenylene bis(2-trifluoromethylacrylate): $2.5 \mathrm{mmol}$, solvent: $5 \mathrm{ml}$.

a.termined by size-exclusion chromatography (PSt standards, eluent: THF).

bTetrahydrofuran (THF) soluble part.

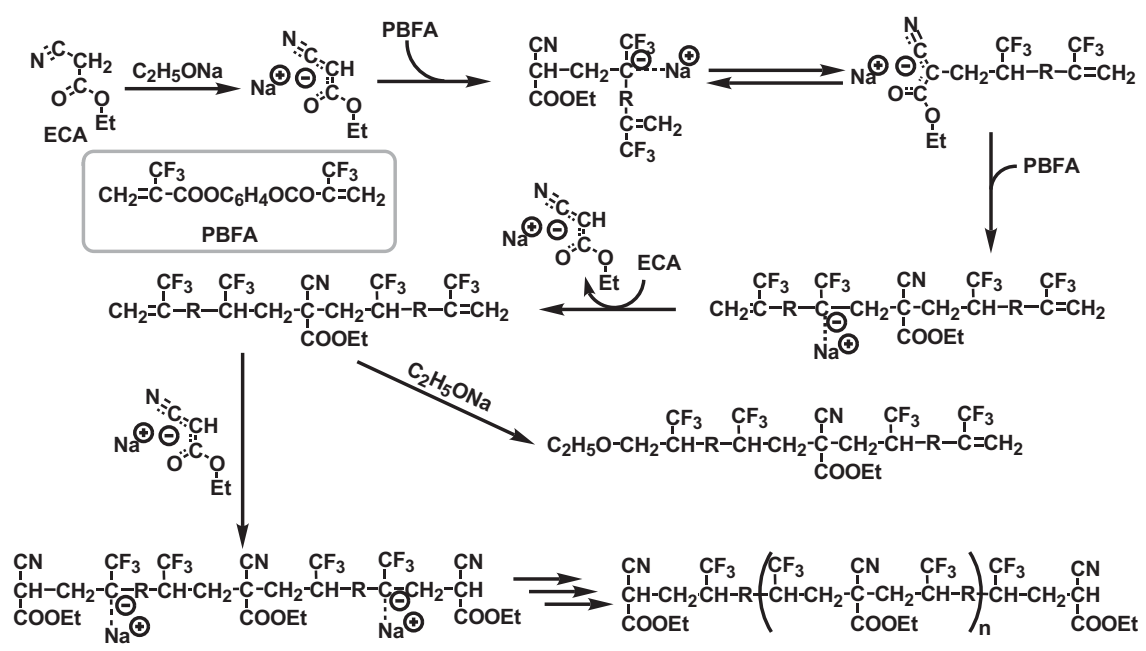

Scheme 2 Anionic polyaddition mechanism of phenylene bis(2-trifluoromethylacrylate) (PBFA) with ethyl cyanoacetate (ECA).

yields with the formation of two carbon-carbon bonds. Therefore, ECA functions as a difunctional compound under specific reaction conditions. The high reactivity of 2-trifluoromethylacrylate as an anion acceptor might make this reaction an appropriate candidate for the preparation of polymers by the double Michael addition. ${ }^{5,9}$

The reaction of phenyl 2-trifluoromethylacrylate $\left(\mathrm{CH}_{2}=\mathrm{C}\left(\mathrm{CF}_{3}\right)\right.$ $\mathrm{COOC}_{6} \mathrm{H}_{5}$ ) with ECA was investigated as a model reaction catalyzed by sodium ethoxide or sodium hydroxide in the presence of excess ECA at $60{ }^{\circ} \mathrm{C}$ for $24 \mathrm{~h}$. The results showed that the di-addition compound of ECA was produced in high yields. Table 5 shows the results of the novel anionic polyaddition of 1,4-phenylene bis(2-trifluoromethylacrylate) $\left(\mathrm{CH}_{2}=\mathrm{C}\left(\mathrm{CF}_{3}\right) \mathrm{COO}-\mathrm{C}_{6} \mathrm{H}_{4}-\mathrm{OCOC}\left(\mathrm{CF}_{3}\right)=\mathrm{CH}_{2}\right)$ with ECA. ${ }^{5,9}$ Increasing the amount of ECA in the feed increases the yields and molecular weights of the polymers obtained (runs 1, 4, 6 and 10) catalyzed by sodium ethoxide in ethanol. The yield and the molecular weight of the resulting polymer are satisfactorily high when ECA is present in significant excess in the feed (run 9). The highest molecular weight obtained is $1.2 \times 10^{4}$ (run 5). Small increases in yields and molecular weights are observed when the amount of sodium ethoxide is increased (runs 10 and 12). The gel formation takes place under sodium hydroxide catalysis (runs 15 and 16). The anionic polyaddition was concluded to take place by the double Michael addition because the NMR spectrum of the polymer was almost the same as that of the di-addition product of the model reaction (Equation (1)). Scheme 2 presents the reaction mechanism. ${ }^{5,9}$ The addition reaction of the ECA anion to the $\alpha$-trifluoromethylvinyl moiety takes place at the polymer chain end, followed by sodium ion transfer to ECA to yield sodium salt again. This cycle may yield the polymer. Further, the groups of polymer chain ends could mainly be cyanoacetate moieties. A trace amount of ethoxide-terminated polymer was detected by NMR measurement. The polyaddition reaction might be terminated when the ethoxide anion is added to the $\alpha$-trifluoromethylvinyl group. 


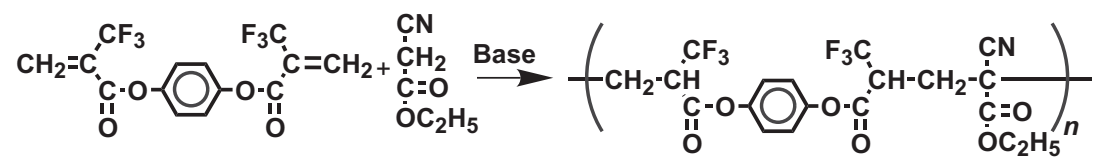

The monomer addition experiment was carried out using ECA moieties at polymer chain ends. The reaction of the isolated polymer was carried out in the presence of 1,4-phenylene bis(2-trifluoromethylacrylate) in the feed catalyzed by sodium ethoxide to obtain results that showed the drastic increase in the molecular weight and the molecular weight distribution compared with those of the starting polymer. The results supported the mechanism in which the polymer end groups were mainly ECA moieties.

The results of the reaction of phenyl 2-trifluoromethylacrylate with acetylacetone catalyzed with sodium hydroxide afforded the di-addition product of acetylacetone in fairly high yields, although addition reactions catalyzed by sodium ethoxide revealed that the yields of the monoaddition compound of acetylacetone were higher than those of the di-addition product. The polyaddition of phenylene bis(2-trifluoromethylacrylate) with acetylacetone catalyzed by sodium hydroxide yielded results indicating that the polymers were obtained bearing the highest molecular weight of $7.6 \times 10^{3}$ in tetrahydrofuran as a solvent with $29 \%$ yield.

Another type of anionic polyaddition was achieved by the reaction of the compound possessing a trifluorovinyl group and a hydroxyl group under basic conditions, as shown in Equation (2) reported by a DuPont research group. ${ }^{2}$ The addition of nucleophiles to fluorinated olefins is among the best-known reactions in organofluorine chemistry. The preferred polymerization catalysts were cesium carbonate, cesium fluoride and tetraalkylammonium chloride, affording molecular weights of about $2.5 \times 10^{4}$ under neat conditions to avoid the formation of cyclic products. Cyclic dimers were mainly produced in 1,2-dimethoxyethane in fairly high yields. with the formation of carbon-carbon bonds from carbon-hydrogen bonds as functional groups. This represents another challenging field of research in macromolecular synthesis.

\section{RADICAL POLYADDITION OF PERFLUOROISOPROPENYL COMPOUNDS}

In 1991, then Professor Nakai at the Tokyo Institute of Technology called to talk about the study on the reactivity of the vinyl group in BPFP, which was synthesized easily by the reaction of lithium enolate obtained from 1,1,1,3,3,3-hexafluoroisopropanol $\left(\left(\mathrm{CF}_{3}\right)_{2} \mathrm{CHOH}\right)$ with two equivalents of butyllithium, followed by the reaction with benzoyl chloride. Addition polymerization of BPFP followed by hydrolysis of the polymer could yield polymers of hydrophobic fluorinated main chains with hydrophilic hydroxyl substituents.

The radical addition polymerization of BPFP was examined, but as anticipated, all attempts were unsuccessful as far as an addition polymerization was concerned. An attractive result was attained when the reaction was carried out in tetrahydrofuran media initiated with benzoyl peroxide and followed by the mass spectrometric measurement of a trace amount of the product. The molecular ion peak was exactly in accordance with the molecular weight of the 1:1 addition product of BPFP with tetrahydrofuran (Equation (3)). The reaction in toluene afforded similar results, which showed that the product was the addition compound possessing a benzyl group. The reaction of BPFP was then investigated with several organic compounds possessing carbon-hydrogen bonds under the same conditions to determine the quantitative conversions of BPFP with compounds such as cycloalkanes, 18-crown-6 and formylalkanes.

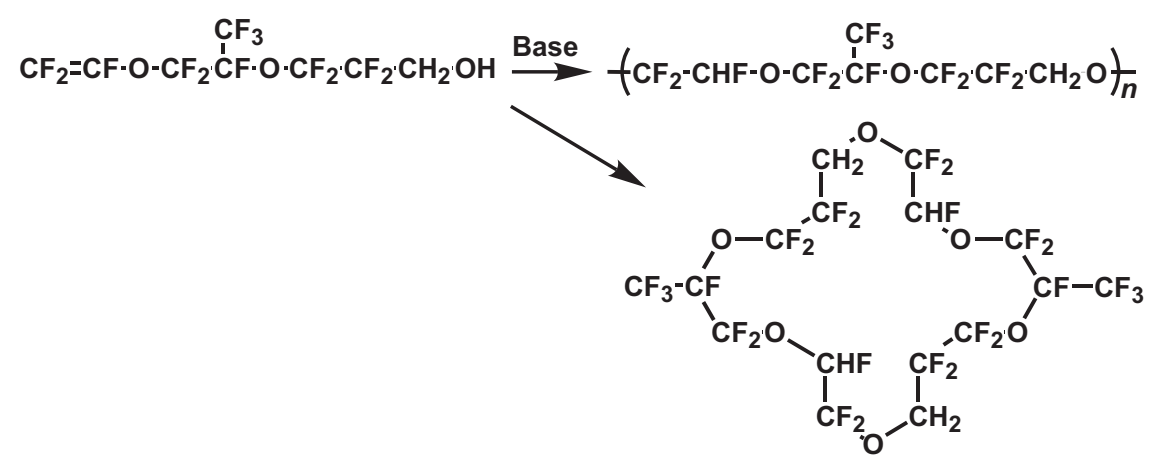

The results demonstrate that anionic polyaddition by the development of the double Michael addition reaction affords a facile method for the preparation of novel fluorine-containing polymers with carbon-carbon bond formation, which is achieved with the aid of the trifluoromethyl group of the vinyl monomer. The reaction establishes a new field in synthetic macromolecular chemistry. It should be noted that the novel polyaddition reaction is successful, although the yields of the product fitting to the polyaddition are not quantitative in the model reaction. Furthermore, the polyaddition reaction takes place under the stoichiometric imbalance of the two components in the feed. The high reactivity of fluorinated vinyl monomers as anion acceptors would make it possible to produce new type of polymers
The idea hit me strongly that the addition reaction of a perfluoroisopropenyl group would be a good candidate for polymer preparation by adopting bifunctional bis(perfluoroisopropenyl) derivatives $\left(\mathrm{CF}_{2}=\mathrm{C}\left(\mathrm{CF}_{3}\right)-\mathrm{R}-\mathrm{C}\left(\mathrm{CF}_{3}\right)=\mathrm{CF}_{2}\right)$ with several organic compounds possessing carbon-hydrogen bonds. ${ }^{3,5,10}$

The reaction of BPFP with 1,4-dioxane was examined as a model to afford 2,6-disubstituted 1,4-dioxane detected by X-ray crystallographic analysis (Figure 4$)^{10}$ as depicted in Equation (4), in contrast to the anticipation that 2,5-disubstituted dioxane would be produced because no 2,5-disubstituted tetrahydrofuran was yielded by the reaction of BPFP with tetrahydrofuran and no addition reaction of isolated monosubstituted tetrahydrofuran took place with BPFP (Equation (3)). 


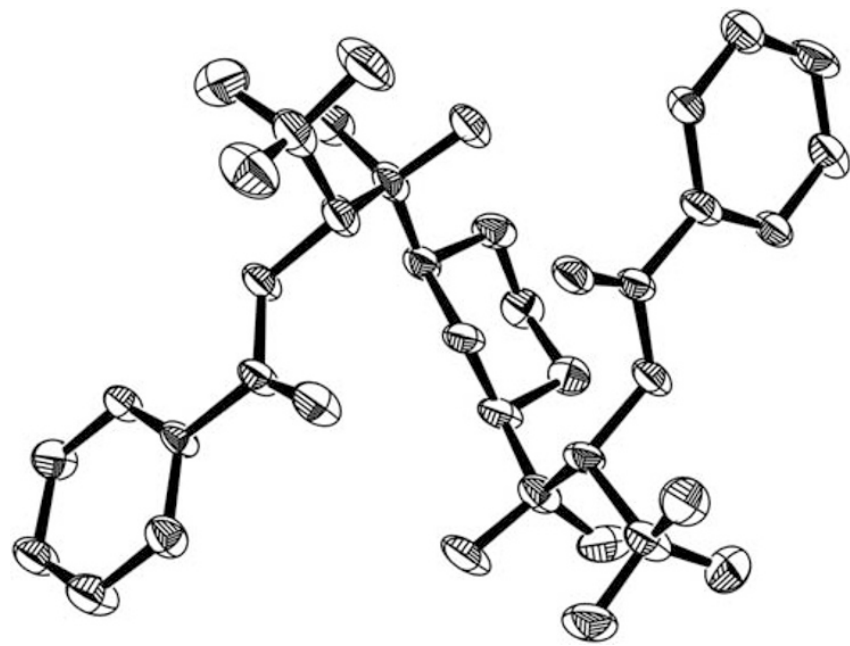

Figure 4 Ortep drawing of di-addition product of 2-benzoxypentafluoropropene (BPFP) with 1,4-dioxane.

In the reaction of monofunctional BPFP with 1,4-dioxane, the mole ratio of 1:1 and 2:1 addition products is found to be about 1:5 as shown in Figure $5 .^{10}$ The precise 1,5-radical shift mechanism is proposed as depicted in Scheme 3. ${ }^{10}$ The mutual repulsion between two fluorine atoms may sterically assist the mechanism of 1,5-radical transfer.

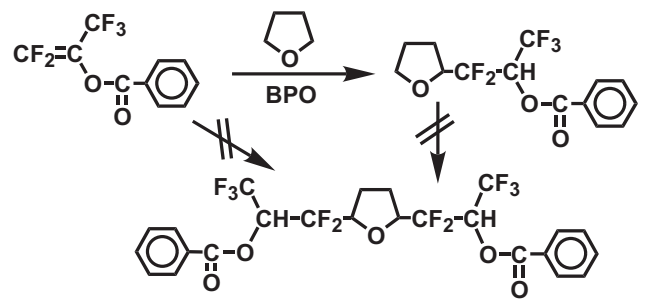

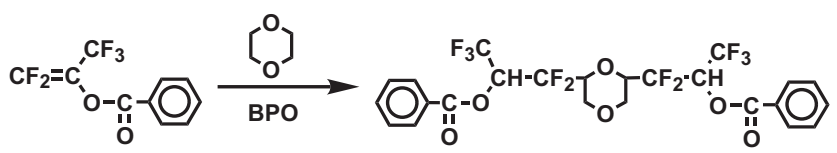

Bis(1-trifluoromethyl-2,2-difluorovinyl) terephthalate $\left(\mathrm{CF}_{2}=\mathrm{C}\left(\mathrm{CF}_{3}\right)\right.$ OCO $\left.-\mathrm{C}_{6} \mathrm{H}_{4}-\mathrm{COOC}\left(\mathrm{CF}_{3}\right)=\mathrm{CF}_{2} ; \mathrm{BFP}\right)$ was synthesized from terephthaloyl dichloride in a similar manner as BPFP. Radical polyaddition of BFP yielded polymers with molecular weights of up to $9.9 \times 10^{3}$ in the presence of an eightfold excess of 1,4-dioxane in the feed initiated with benzoyl peroxide at $60^{\circ} \mathrm{C}$. The polyaddition equation is shown as Equation (5), and the proposed mechanism is depicted in Scheme $4 .{ }^{10}$ The reaction is initiated by the abstraction of hydrogen from 1,4dioxane and then the addition of the resulting radical to the perfluoroisopropenyl group, followed by a 1,5-radical shift.

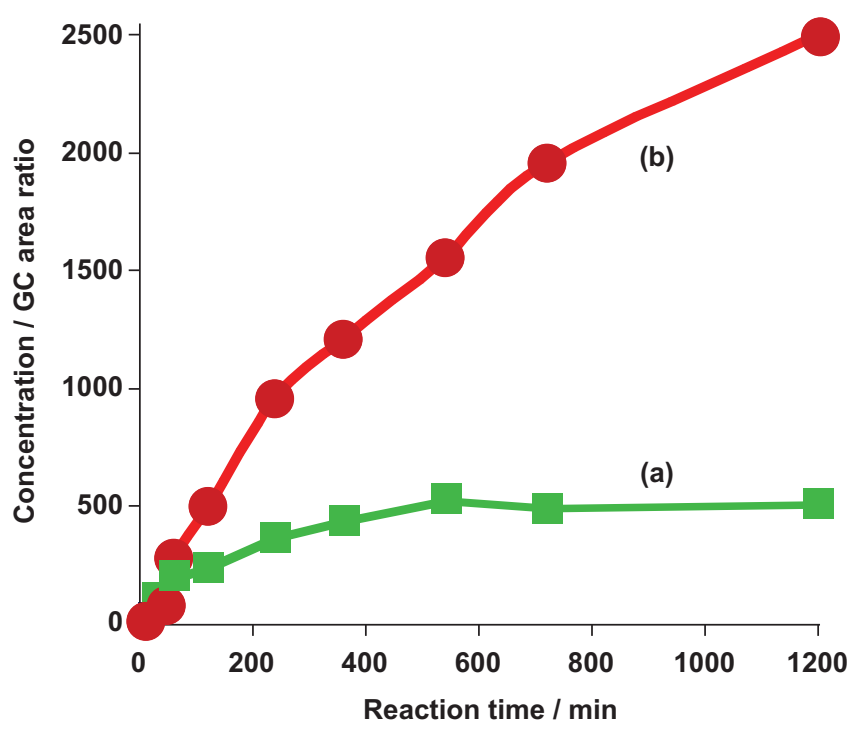

Figure 5 Dependence of (a) $1: 1$ and (b) 2:1 addition products of 2-benzoxypentafluoropropene (BPFP) with 1,4-dioxane on reaction time.

The reaction may be promising, as it would enable simple introduction of fluoroalkyl groups into organic compounds and polymer main chains. It should be noted that the reaction takes place under a stoichiometric imbalance between the two feed components, and yields of the product fitting to polyaddition were not quantitative in model reactions. It may also be advantageous that $1,1,1,3,3,3$-hexafluoroisopropanol is readily available at a fairly low price and will always be commercially available because the compound is scarcely related to fluorine-containing refrigerants.

The radical polyaddition reaction might be applicable to a wide variety of organic compounds possessing carbon-hydrogen bonds that have never been used as starting materials for the preparation of polymers. Several studies have been conducted on the radical polyaddition of perfluoroisopropenyl compounds. The following discussion provides examples of radical polyaddition from these new findings. 5,10

Higher-molecular-weight polymers were expected when the radical polyaddition was carried out under $\gamma$-rays irradiation from a ${ }^{60} \mathrm{Co}$ source, which enables the continuous generation of radical species. The highest weight-average molecular weight polymer of $2.0 \times 10^{4}$ was produced under a dose of $2000 \mathrm{kGy}$ in the presence of eight equivalents of 1,4-dioxane in the feed with BFP. The investigation of the dose dependence on $\bar{M}_{\mathrm{w}}$ yields the results cited in Figure $6,{ }^{10}$ which shows that an eightfold excess of 1,4-dioxane to BFP in the feed is preferable to obtain higher-molecular weight polymers above $2000 \mathrm{kGy}$. The kinetic analysis of the model reactions revealed that the rate constants

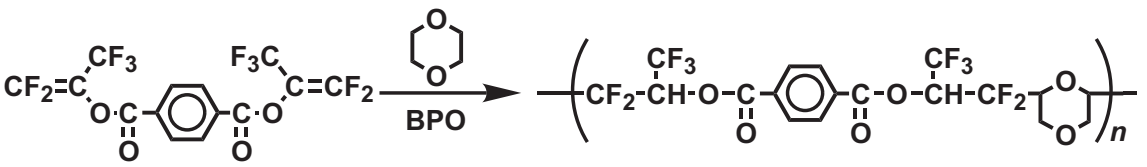




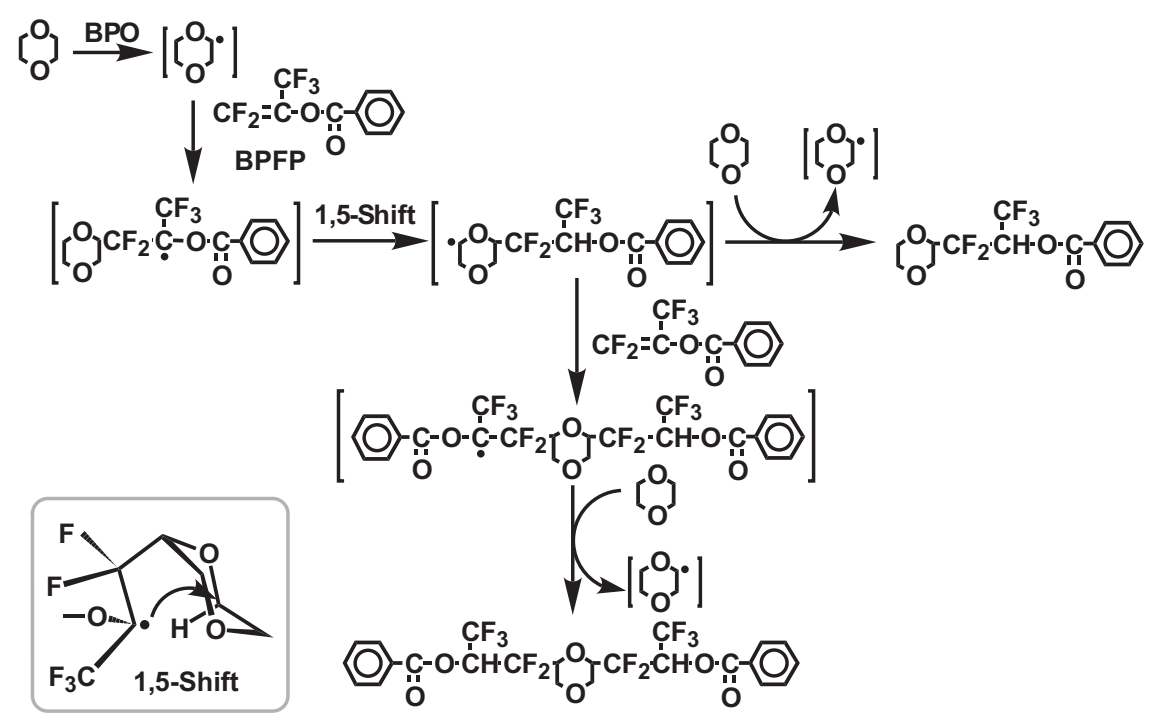

Scheme 3 Radical addition mechanism of 2-benzoxypentafluoropropene (BPFP) with 1,4-dioxane.

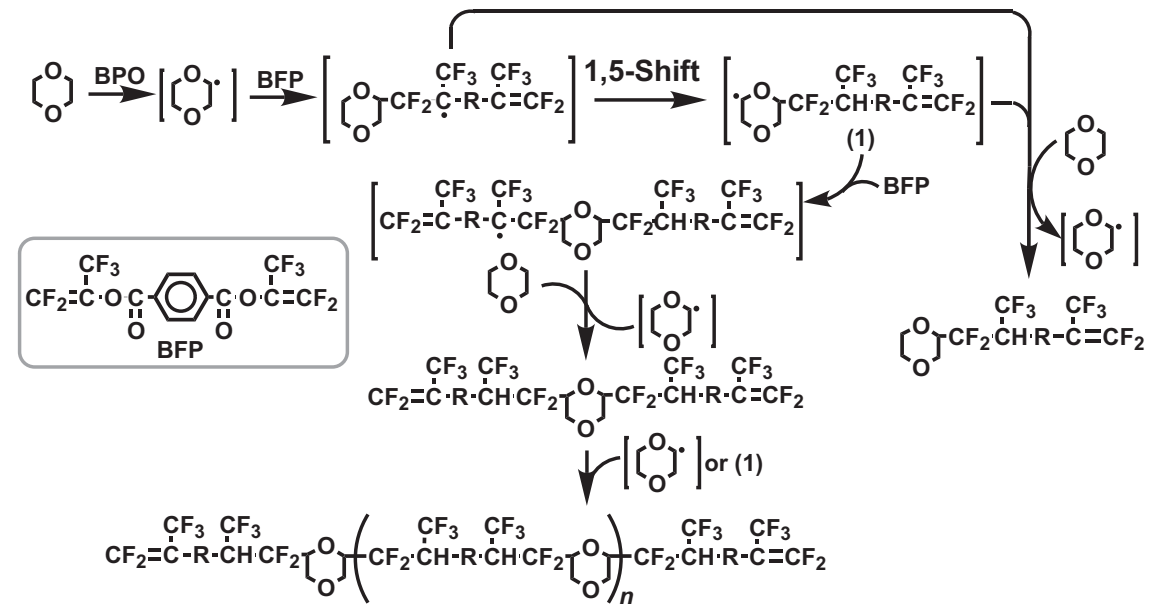

Scheme 4 Polyaddition mechanism of bis(1-trifluoromethyl-2,2-difluorovinyl) terephthalate (BFP) with 1,4-dioxane.

of the formation of 2:1 addition products $\left(k_{\mathrm{d}}\right)$ of BPFP with 1,4dioxane and diethyl ether were two orders of magnitude larger than those of $1: 1$ addition products $\left(k_{\mathrm{m}}\right)$ under the $\gamma$-rays irradiation. The results led to the conclusion that the radiation-induced stepgrowth polymerization required high $k_{\mathrm{d}} / k_{\mathrm{m}}$ values under the stoichiometric imbalance of two components in the feed, as well as the high radiation resistance, to form high-molecular-weight polymers. Polymers prepared from 1,4-dioxane showed higher radiation resistance than those obtained from diethyl ether measured in solid state and in solution.

A polymer of $5.5 \times 10^{3}$ as a molecular weight was obtained from BFP with hexane by the radical polyaddition (Equation (6)) initiated with benzoyl peroxide at $80^{\circ} \mathrm{C}$ for $120 \mathrm{~h}$. Hexane might be the simplest compound bearing carbon-hydrogen bonds. The reaction may take place by the precise 1,5-radical shift mechanism.
Because the radical addition of BPFP with formylalkanes produced addition compounds in quantitative yields as mentioned above, the reaction of BFP with glutaraldehyde was examined under emulsion polymerization conditions because glutaraldehyde was available as an aqueous solution. The reaction initiated by benzoyl peroxide and allowed to proceed at $80^{\circ} \mathrm{C}$ for $72 \mathrm{~h}$ afforded an oligomer of $4.8 \times 10^{3}$ as the highest molecular weight, as shown in Equation (7). The abstraction reaction of the hydrogen of the formyl group may initiate the polyaddition reaction.

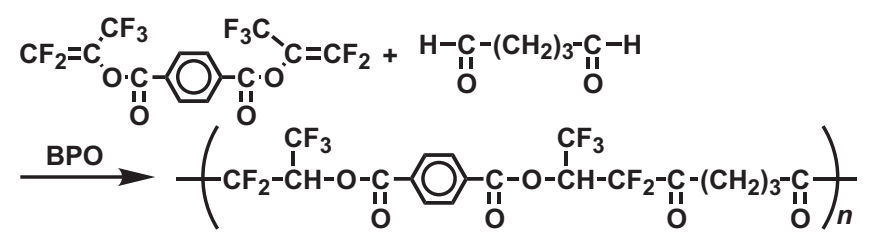

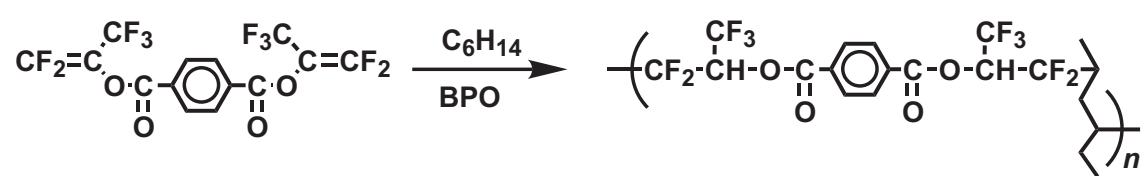




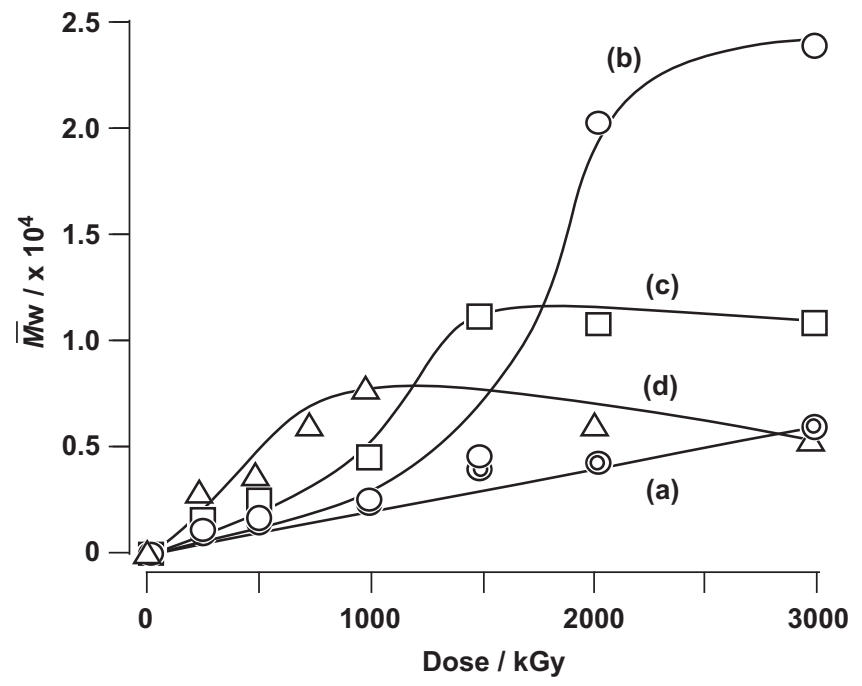

Figure 6 Dependence of the weight-average molecular weight of the polymer obtained on the irradiation dose for feed 1,4-dioxane/bis(1-trifluoromethyl-2,2-difluorovinyl) terephthalate (BFP) values of (a) 4.0, (b) 8.0, (c) 16 and (d) 32 .

It may also be possible to prepare polymers of BFP with multifunctional compounds, such as 18-crown-6, which has 24 carbon-hydrogen bonds, to prove the precise radical shift mechanism of the reaction of BFP with 1,4-dioxane. The reaction was initiated with benzoyl peroxide and carried out at $60^{\circ} \mathrm{C}$ for $72 \mathrm{~h}$, yielding soluble polymers containing 18-crown-6 moieties in the polymer main chain. The highest molecular weight obtained was $5.5 \times 10^{4}$. The reaction takes place as shown in Equation (8). A precise 1,5-radical shift mechanism has not yet been proven, because the structure of the product yielded by the hydrolysis of the polymer has not yet been determined, as described below.

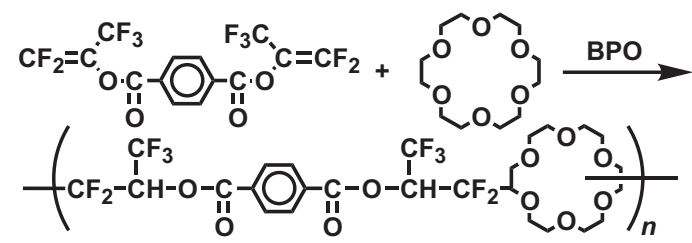

The addition of BPFP with triethylamine afforded ordinary yields as compared with many reports on the radical addition of trifluorovinyl compounds with amine derivatives. ${ }^{4}$ The radical polyaddition of BFP with triethylamine was then examined to yield a polymer of $6.3 \times 10^{3}$ as the highest molecular weight following initiation with benzoyl peroxide and reaction at $60{ }^{\circ} \mathrm{C}$ for
$72 \mathrm{~h}$, as shown in Equation (9), although the yield of polymer was very low.

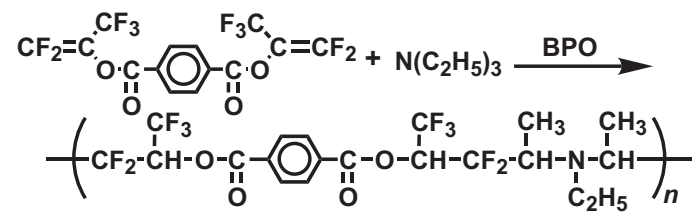

To increase the fluorine content of polymers obtained from BFP with 1,4-dioxane, the copolymerization of BFP and bis(1-trifluoromethyl-2,2difluorovinyl $)$ 2,3,5,6-tetrafluoroterephthalate $\left(\mathrm{CF}_{2}=\mathrm{C}\left(\mathrm{CF}_{3}\right) \mathrm{OCO}-\mathrm{C}_{6} \mathrm{~F}_{4}-\right.$ $\left.\operatorname{COOC}\left(\mathrm{CF}_{3}\right)=\mathrm{CF}_{2}\right)$ with 1,4-dioxane was investigated and shown to afford polymers of molecular weight $1.1 \times 10^{4}$ following initiation with di-tert-butyl peroxide and reaction at $80^{\circ} \mathrm{C}$ for $72 \mathrm{~h}$, as shown in Equation (10). It was likely that the random distribution of BFP units and bis(1-trifluoromethyl-2,2-difluorovinyl) 2,3,5,6-tetrafluoroterephthalate units was possible in the polymer main chain because the monomer reactivity ratios of bis(1-trifluoromethyl-2,2-difluorovinyl) 2,3,5,6-tetrafluoroterephthalate $\left(\mathrm{M}_{1}\right)$ and BFP $\left(\mathrm{M}_{2}\right)$ were $r_{1}=1.19, r_{2}=0.78$ and $r_{1} \times r_{2}=0.93$, which is smaller than 1 , and the reactivity of BPFP was similar to that of 2-pentafluorobenzoxypentafluoropropene $\left(\mathrm{CF}_{2}=\right.$ $\left.\mathrm{C}\left(\mathrm{CF}_{3}\right) \mathrm{OCOC}_{6} \mathrm{~F}_{5}\right)$ examined as a model reaction.

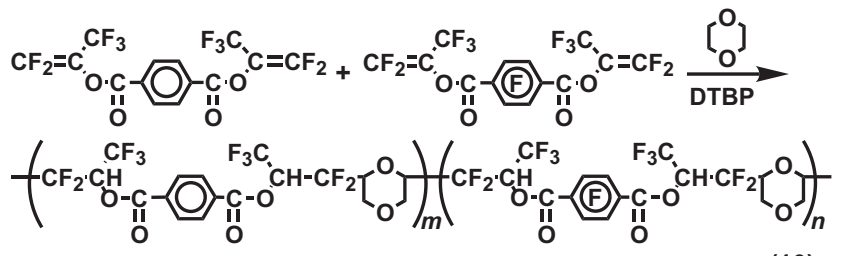

The radical polyaddition reaction could be developed to the synthesis of fluorinated hybrid polymers bearing alkylsilyl groups in polymer main chains because many organosilicone compounds possess carbon-hydrogen or silicon-hydrogen bonds. The reactions of diethoxydimethylsilane $\left(\left(\mathrm{C}_{2} \mathrm{H}_{5} \mathrm{O}\right)_{2} \mathrm{Si}\left(\mathrm{CH}_{3}\right)_{2}\right)$ and dimethoxydimethylsilane $\left(\left(\mathrm{CH}_{3} \mathrm{O}\right)_{2} \mathrm{Si}\left(\mathrm{CH}_{3}\right)_{2}\right)$ with BPFP were examined as model reactions initiated by benzoyl peroxide or di-tert-butyl peroxide. The yield of the 2:1 addition product of BPFP with diethoxydimethylsilane was found to be higher than that of BPFP with dimethoxydimethylsilane. The polyaddition of BFP with diethoxydimethylsilane was successful, affording fluorinated hybrid polymers possessing fluoroalkyl and alkylsilyl groups in the polymer main chain with a maximum molecular weight of $1.4 \times 10^{4}$. The reaction takes place as depicted in Equation (11). The 1,7-radical shift mechanism, which has rarely been observed in organic reactions, would take place in the addition reaction of BPFP with diethoxydimethylsilane to produce the 2:1 addition product. The 1,7-radical shift mechanism should also take place in the polyaddition of BFP with diethoxydimethylsilane as shown in Scheme $5 .{ }^{10}$

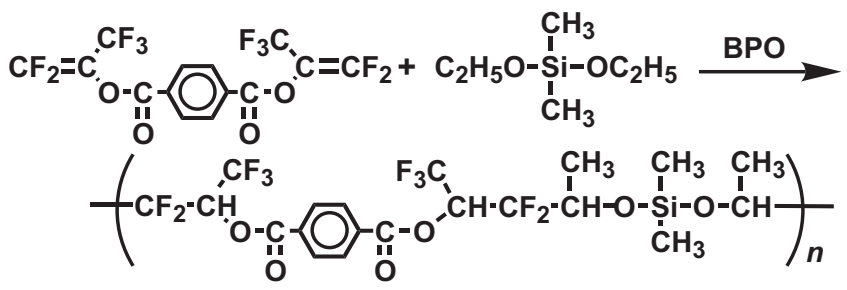




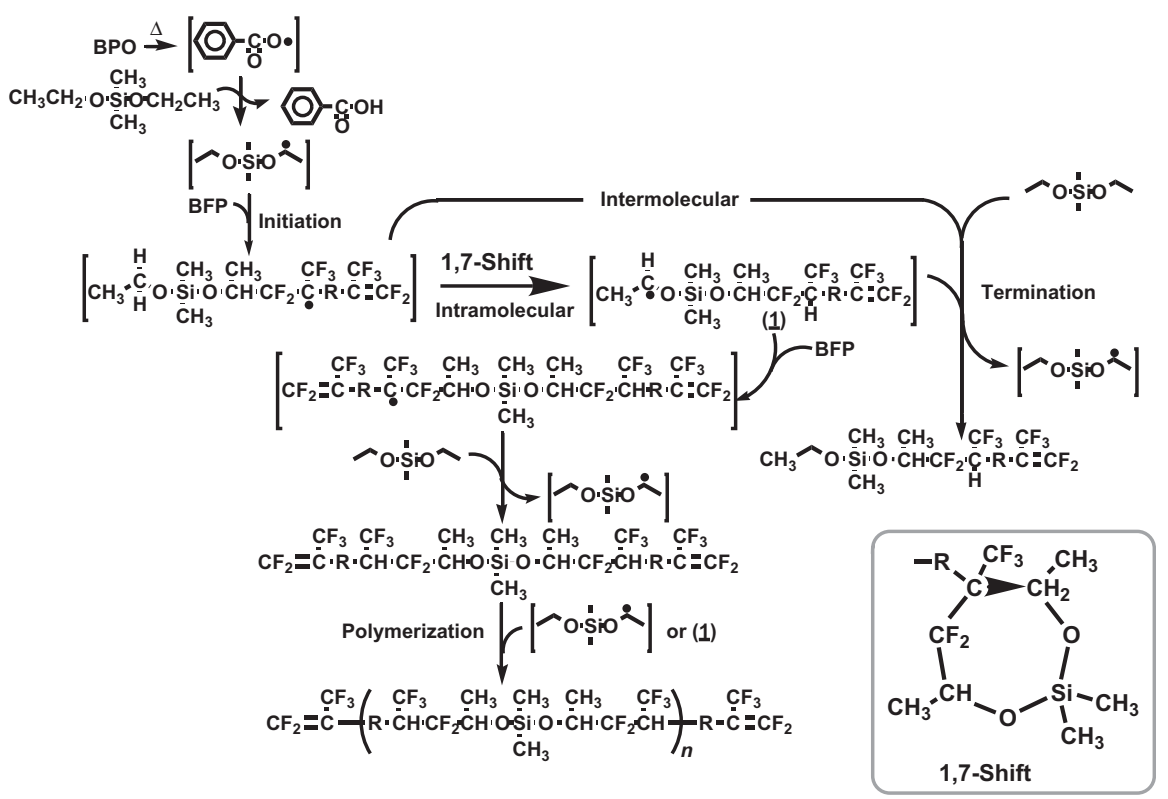

Scheme 5 Polyaddition mechanism of bis(1-trifluoromethyl-2,2-difluorovinyl) terephthalate (BFP) with diethoxydimethylsilane.

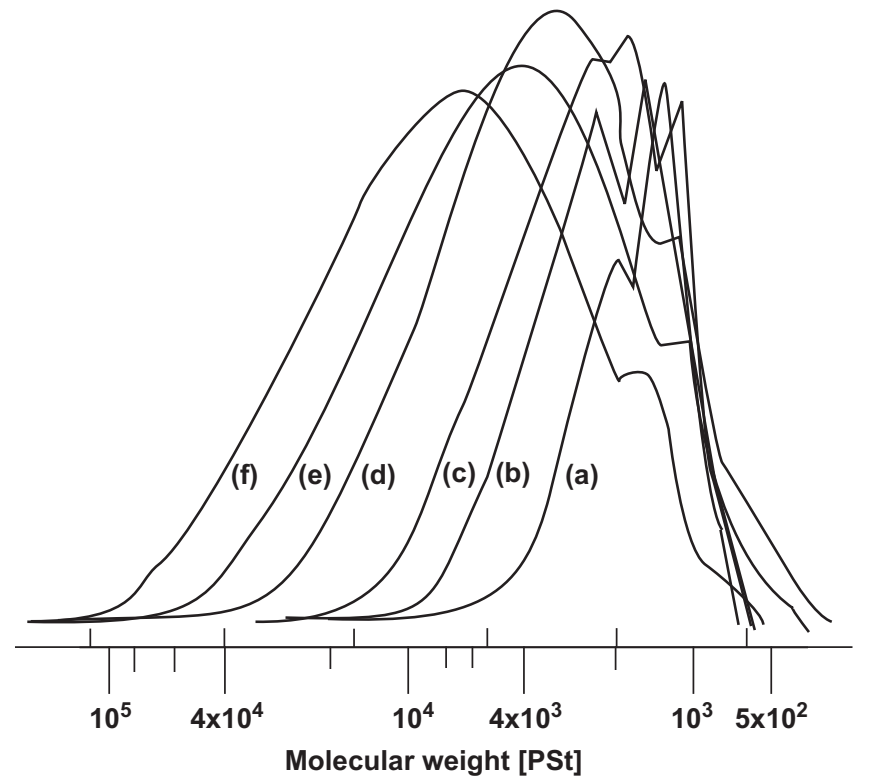

Figure 7 Reaction-time dependence of the molecular weight and molecular weight distribution, and polymer yield of the reaction of bis(1-trifluoromethyl2,2-difluorovinyl) terephthalate (BFP) $(5.0 \mathrm{mmol})$ with diethoxydimethylsilane $(40 \mathrm{mmol})$ initiated with benzoyl peroxide $(1.0 \mathrm{mmol})$ at $80^{\circ} \mathrm{C}$ : (a) $2 \mathrm{~h}, 46 \%$; (b) $4 \mathrm{~h}, 68 \%$; (c) $6 \mathrm{~h}, 78 \%$; (d) $12 \mathrm{~h}, 89 \%$; (e) $22 \mathrm{~h}, \approx 100 \%$; and (f) $40 \mathrm{~h}, 100 \%$.

The dependence of reaction time on the molecular weight and the molecular weight distribution was examined for the polyaddition of BFP with diethoxydimethylsilane. The results are summarized in Figure $7,{ }^{10}$ which shows that molecular weights and molecular weight distributions increase with reaction time. The molecular weight also increases and the molecular weight distribution becomes broader after the conversion of BFP reaches $100 \%$. These phenomena are often found in step-growth polymerization reactions such as condensation polymerization. Therefore, a longer reaction time may be preferable to obtain higher-molecular weight polymers based on the kinetics of condensation polymerization, and a lower reaction temperature is also desirable to ensure that the radical initiator is active longer.

Soluble fluorinated hybrid polymer was obtained from BFP with tetrafunctional tetraethoxysilane $\left(\mathrm{Si}\left(\mathrm{C}_{2} \mathrm{H}_{5} \mathrm{O}\right)_{4}\right)$ initiated by di-tert-butyl peroxide and proceeded at $120^{\circ} \mathrm{C}$ for $72 \mathrm{~h}$, as shown in Equation (12). The highest molecular weight obtained was $8.2 \times 10^{3}$ and the yield was fairly high. The 1,7 -radical shift mechanism might also take place in the polyaddition of BFP with tetraethoxysilane.

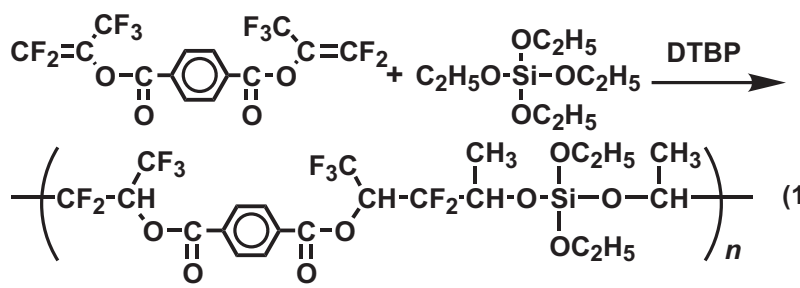

Another soluble fluorinated hybrid polymer bearing alkylsilyl groups in polymer main chains was synthesized from BFP with multifunctional silsesquioxane such as $1,3,5,7,9,11,13,15$-octakis(dimethylsilyloxy)pentacyclo[9.5.1.1 $\left.1^{3,9} \cdot 1^{5,15} \cdot 1^{7,13}\right]$ octasiloxane $\left(\mathrm{T}_{8} \mathrm{~S}\right)$. The highest molecular weight obtained was $1.4 \times 10^{4}$ by the initiation with benzoyl peroxide and the reaction at $80^{\circ} \mathrm{C}$. The reaction takes place as shown in Equation (13). The 1,9-radical shift mechanism would take place in the reaction of BFP with $\mathrm{T}_{8} \mathrm{~S}$ as depicted in Scheme $6 .{ }^{10}$ The reaction mechanism proves that the polyaddition reaction takes place through the silyl radical as a reactive intermediate. The 1,9-radical shift mechanism has rarely been reported in organic reactions. 


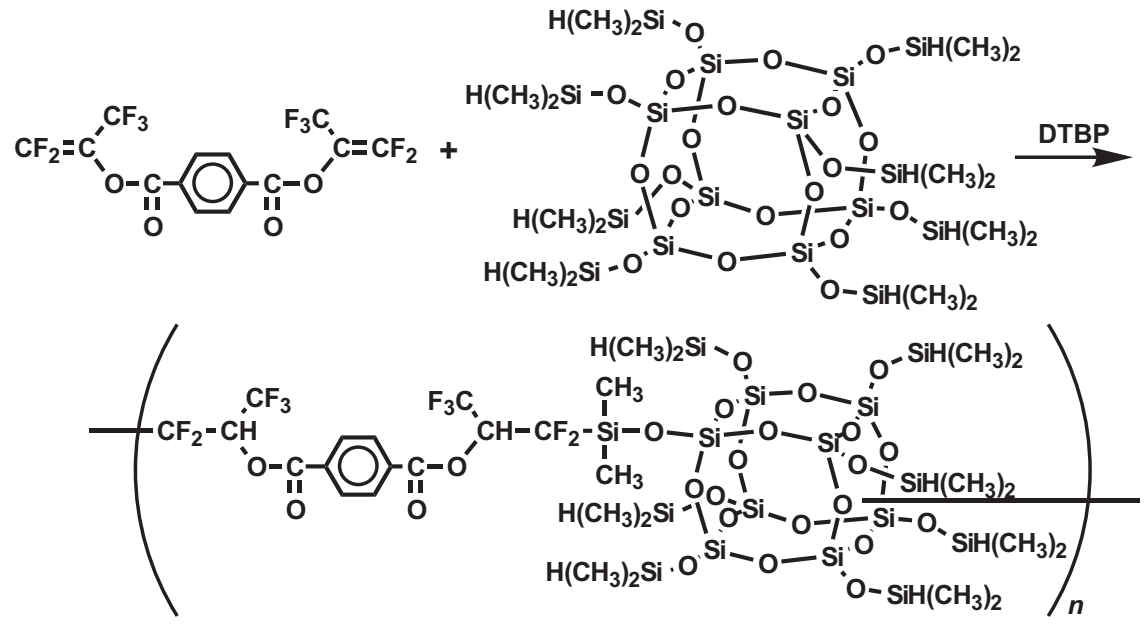

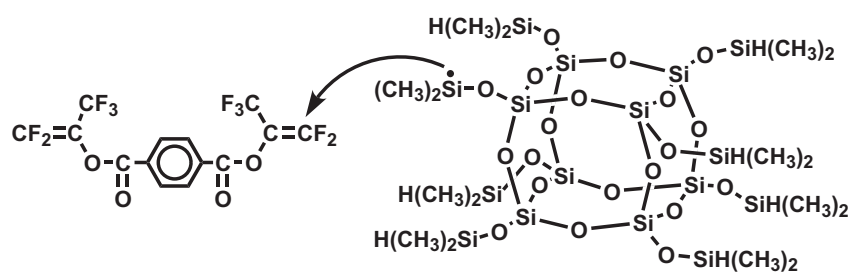

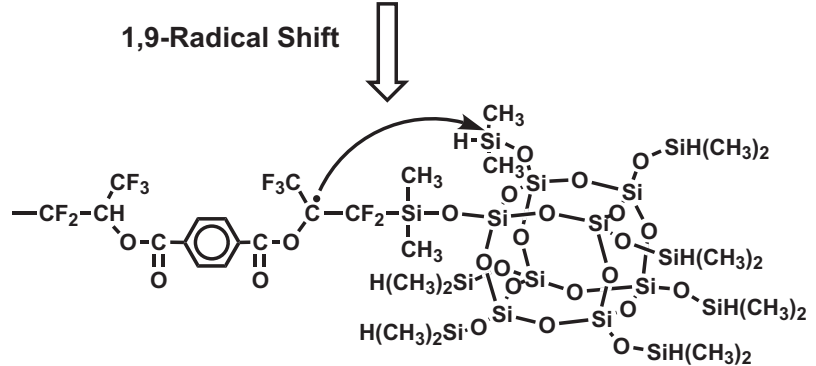

Scheme 6 Polyaddition mechanism of bis(1-trifluoromethyl-2,2-difluorovinyl) terephthalate (BFP) with $\mathrm{T}_{8} \mathrm{~S}$.

The novel radical polyaddition reaction mentioned above took place intermolecularly between perfluoroisopropenyl compounds and organic compounds possessing carbon-hydrogen bonds under a stoichiometric imbalance in the feed. The next step should be to develop a selfpolyaddition reaction in which an intramolecular polyaddition takes place on a molecule possessing both a perfluoroisopropenyl group and an alkylsilyl group bearing many carbon-hydrogen bonds. To attempt this reaction, triethylsilyl perfluoroisopropenyl ether $\left(\mathrm{CF}_{2}=\mathrm{C}\left(\mathrm{CF}_{3}\right) \mathrm{O}\right.$ $\left.\mathrm{Si}\left(\mathrm{C}_{2} \mathrm{H}_{5}\right)_{3}\right)$ was synthesized by the reaction of lithium enolate obtained from 1,1,1,3,3,3-hexafluoroisopropanol with two equivalents of butyllithium, followed by adding one equivalent of triethylsilyl chloride. The polymer was obtained with a molecular weight up to $1.9 \times 10^{4}$ by initiation with benzoyl peroxide allowing to proceed at $80^{\circ} \mathrm{C}$ for $40 \mathrm{~h}$ as shown in Equation (14), and this may occur by the intramolecular 1,5radical shift. The detailed reaction profile was studied by the dependence of reaction time on the molecular weight and molecular weight distribution, as shown in Figure $8 .{ }^{10}$ Polymers with molecular weights of $9.8 \times 10^{3}$ are obtained with unimodal molecular weight distributions $\left(\bar{M}_{\mathrm{w}} / \bar{M}_{\mathrm{n}}: 1.55\right)$ at the early stage of polymerization up to $36 \%$ conversions. The portion of the reaction seems to resemble a traditional radical chain reaction profile for typical vinyl polymerizations. After this point,

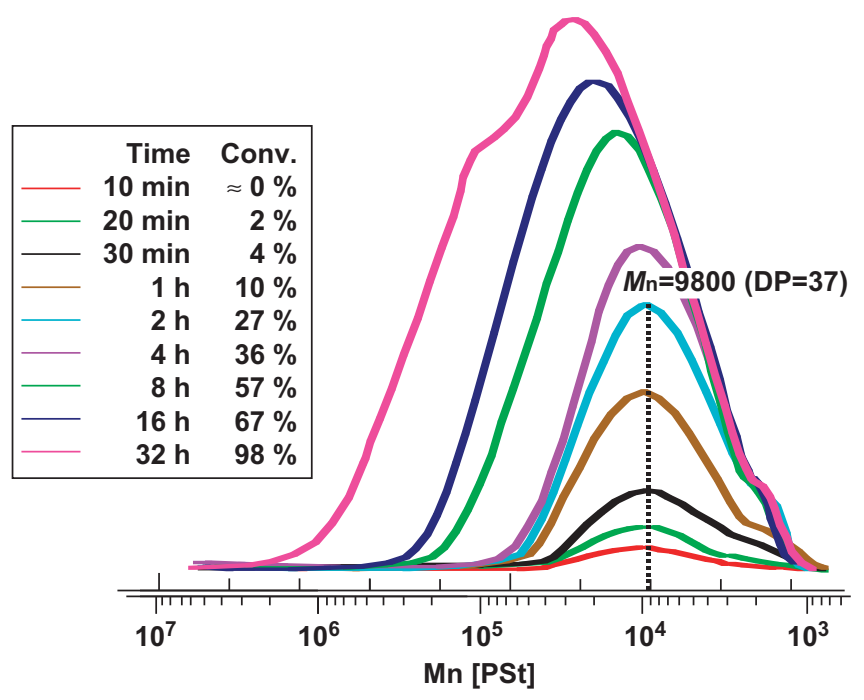

Figure 8 Reaction-time dependence of the molecular weight and molecular weight distribution of triethylsilyl perfluoroisopropenyl ether.

the molecular weights and molecular weight distributions increase with reaction time. This shows that the coupling reaction of the radicals at the ends of the propagating polymers takes place in addition to the propagation reaction with triethylsilyl perfluoroisopropenyl ether.

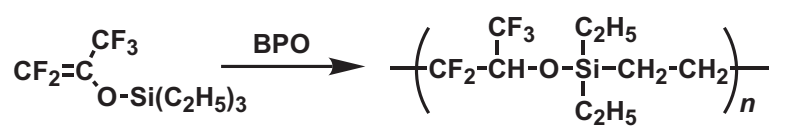

The preparation of a polymer from 1-trifluoromethyl-2,2-difluorovinyl cyclohexanecarboxylate $\left(\mathrm{CF}_{2}=\mathrm{C}\left(\mathrm{CF}_{3}\right) \mathrm{OCO}-\mathrm{C}_{6} \mathrm{H}_{11}\right)$ was unsuccessful, probably because of the low feed ratio of the group bearing carbon-hydrogen bonds to the perfluoroisopropenyl group in combination with the restricted structure of cyclohexane.

Another potential route for self-polyaddition is the cyclopolymerization of a compound with a perfluoroisopropenyl group and a vinyl group retaining no homopolymerization ability. Perfluoroisopropenyl vinylacetate $\left(\mathrm{CH}_{2}=\mathrm{CHCH} \mathrm{COOC}_{2}\left(\mathrm{CF}_{3}\right)=\mathrm{CF}_{2}\right)$ was synthesized because the allyl group was known to possess a poor radical polymerization ability due to degradable chain transfer under radical reaction conditions. 
The radical cyclopolymerization of the compound resulted in a bimodal molecular weight distribution with peaks of high-molecular-weight polymers at about $1 \times 10^{5}$ and of low-molecular-weight oligomers of $7 \times 10^{3}$. The yields of oligomers were higher than those of polymers. The reaction products were soluble in acetone, tetrahydrofuran and ethyl acetate and insoluble in methanol, ethanol, hexane, benzene and chloroform. The structure of the polymer was similar to that of the oligomer, which consisted of about $70 \%$ of a five-membered ring structure. The reaction may take place through an intramolecular 1,5-radical addition reaction as shown in Equation (15), although it remains unclear why the reaction products exhibited a bimodal molecular weight distribution. The hydrolysis of the cyclopolymerization product yielded polymers possessing a hydrophobic pentafluoroisopropyl group and hydrophilic hydroxyl and carboxyl groups in each monomer unit, also as depicted in Equation (15). The hydrolyzed product was soluble in methanol, ethanol, acetone, tetrahydrofuran and ethyl acetate, and insoluble in hexane, benzene, chloroform and water.

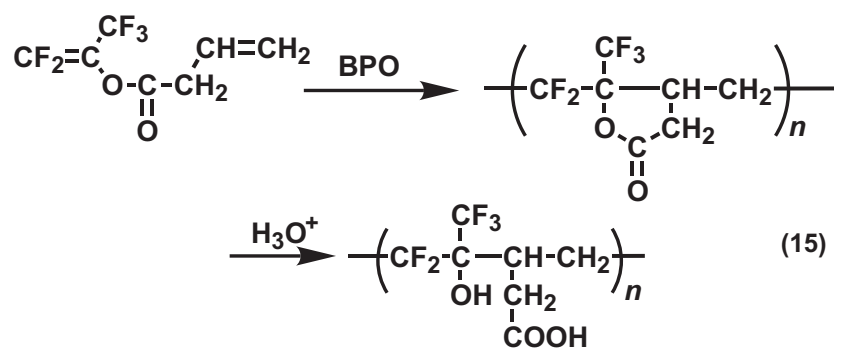

Furthermore, a synthesis of a polymer with a six-membered ring structure in the main chain was investigated by the radical cyclopolymerization of 4-pentenoyloxypentafluoropropene $\left(\mathrm{CH}_{2}=\mathrm{CHCH}_{2}\right.$ $\left.\mathrm{CH}_{2} \mathrm{COOC}\left(\mathrm{CF}_{3}\right)=\mathrm{CF}_{2}\right)$, containing one additional methylene group compared with perfluoroisopropenyl vinylacetate. Contrary to expectations, vinyl polymerization was found to take place instead of cyclopolymerization when the reaction was initiated with benzoyl peroxide or di-tert-butyl peroxide, as shown in Equation (16). The highest molecular weight polymer obtained was $1.8 \times 10^{4}$ when the reaction was initiated with di-tert-butyl peroxide and proceeded at $100{ }^{\circ} \mathrm{C}$ for $72 \mathrm{~h}$. The polymerization could be initiated by the addition of phenyl or benzoxy radicals as a phenyl group was detected by ${ }^{1} \mathrm{H}$ and ${ }^{13} \mathrm{C}$ NMR when the reaction was initiated with benzoyl peroxide. The initiation reactions are described later in more detail. The degree of polymerization was 23 as calculated from the integrated ratio of phenyl protons to methylene protons determined by ${ }^{1} \mathrm{H}$ NMR, which was in agreement with the degree of polymerization of 38 calculated from the measurement of the same polymer by size-exclusion chromatography. The results suggested that the termination took place by a radical recombination reaction. The polymer would retain functional groups as an anchor that can react with a wide variety of organic compounds because each monomer unit possesses a perfluoroisopropenyl group in the polymer side chain. The addition polymerization of the allyl group to yield a high-molecular-weight polymer may have serendipitously produced a polymer possessing functional groups.

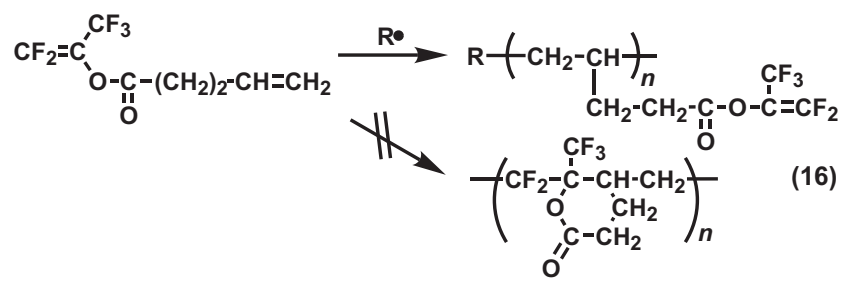

The radical polyaddition of BFP produces soluble polymers with multifunctional compounds such as 18-crown-6, triethylamine and tetraethoxysilane because of a precise radical shift mechanism as mentioned above. It should be beneficial to know how a multifunctional perfluoroisopropenyl compound would behave in a similar reaction. Tris(1-trifluoromethyl-2,2-difluorovinyl) 1,3,5-benzenetricarboxylate $\left(\mathrm{C}_{6} \mathrm{H}_{3}\left(\mathrm{COOC}\left(\mathrm{CF}_{3}\right)=\mathrm{CF}_{2}\right)_{3}\right)$ was synthesized, and the radical polyaddition was examined with diethoxydimethylsilane. The soluble polymer was obtained with $1.1 \times 10^{4}$ as the highest molecular weight in low yields when the reaction was initiated with di-tert-butyl peroxide and allowed to proceed at $120^{\circ} \mathrm{C}$ for $72 \mathrm{~h}$, although the conversion of the perfluoroisopropenyl compound was almost quantitative. The reaction takes place as shown in Equation (17) according to the measurements of the polymer by NMR. The polymer possesses a perfluoroisopropenyl group in each monomer unit as an anchor that can react with a wide variety of functional organic compounds. The polyaddition of tris(1-trifluoromethyl-2,2-difluorovinyl) 1,3,5-benzenetricarboxylate produced a soluble oligomer with a molecular weight of $2 \times 10^{3}$ with 18 -crown- 6 .

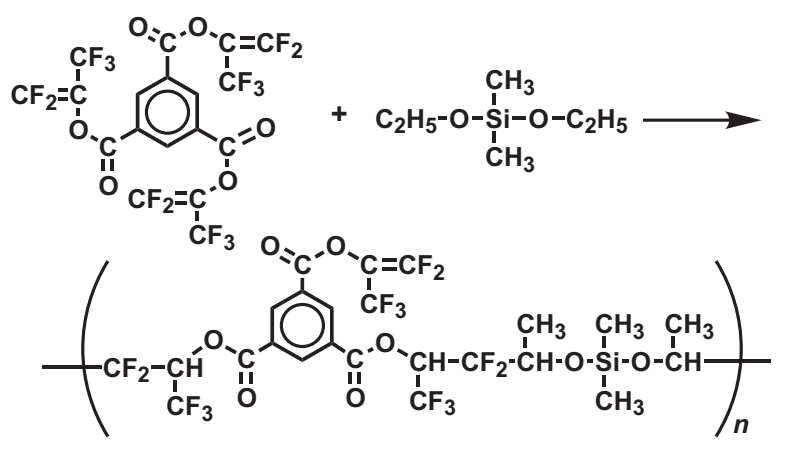

To clarify the initiation reaction of the radical polyaddition introduced here, the reactions of BPFP and dimethylphenylsilyl perfluoroisopropenyl ether $\left(\mathrm{C}_{6} \mathrm{H}_{5} \mathrm{Si}\left(\mathrm{CH}_{3}\right)_{2} \mathrm{OC}\left(\mathrm{CF}_{3}\right)=\mathrm{CF}_{2}\right)$ were monitored as a model of triethylsilyl perfluoroisopropenyl ether in the presence of benzoyl peroxide by gas chromatography and ${ }^{19} \mathrm{~F}$ NMR. The results are shown in Figure 9. ${ }^{10}$ The concentration of dimethylphenylsilyl perfluoroisopropenyl ether decreases with reaction time. The addition reaction of phenyl or benzoxy radicals from benzoyl peroxide takes place, probably because the reactivity of the perfluoroisopropenyl group is enhanced by the electron-donating effect of a siloxy group in connection with the electron-withdrawing effect of the fluoroalkyl group. No addition reaction takes place in the case of BPFP. The hydrogen abstraction reaction is therefore proven to be the initiation reaction of the polyaddition of BFP with organic compounds such as 1,4-dioxane, 18-crown-6, hexane, glutaraldehyde, triethylamine, diethoxydimethylsilane and tetraethoxysilane. The results also support the mechanisms shown in Schemes 3 and 4 . The initiation by the radical addition may take place in the reaction systems of triethylsilyl perfluoroisopropenyl ether, perfluoroisopropenyl vinylacetate and 4-pentenoyloxypentafluoropropene.

The initiator efficiency was determined by measuring the induction period of the reaction of triethylsilyl perfluoroisopropenyl ether in the presence of 1,1-diphenyl-2-picrylhydrazyl. The initiator efficiency was determined as $0.30 \pm 0.02$, which is an extremely low value considering the fact that the initiator efficiency is $0.8-1.0$ in the standard vinyl polymerization initiated by benzoyl peroxide, probably because of the cage effect of an initiation system surrounded by fluorinated molecules. 


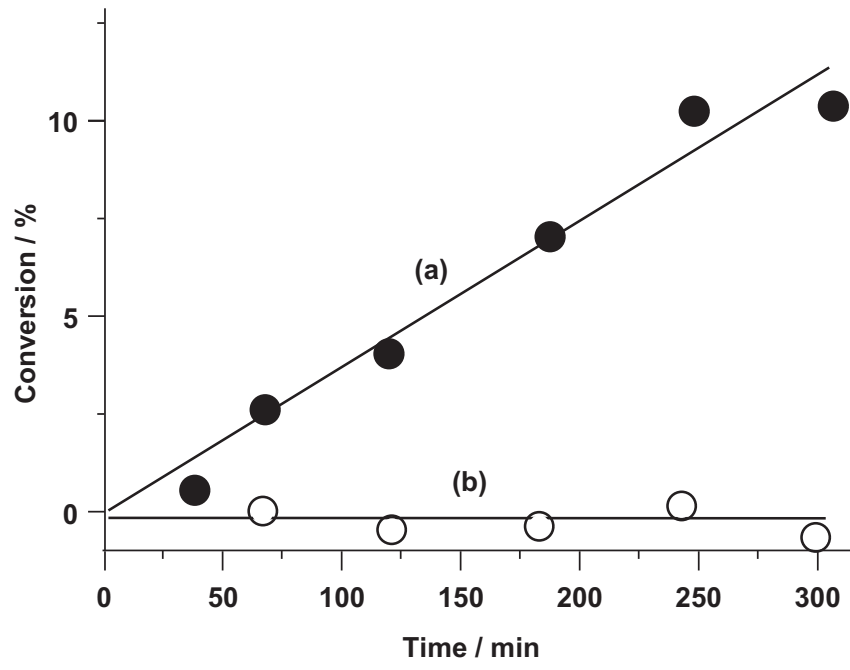

Figure 9 Time dependence of (a) dimethylphenylsilyl perfluoroisopropenyl ether, and (b) 2-benzoxypentafluoropropene (BPFP) on conversion with benzoyl peroxide $(12 \mathrm{~mol} \%)$ at $80^{\circ} \mathrm{C}$.

In conclusion, several fluorinated polymers were synthesized by the novel radical polyaddition method, and rare reaction mechanisms such as 1,7- and 1,9-radical shifts were demonstrated. Some of these reaction mechanisms have been summarized in previous review articles. $^{5,10}$ The synthesis of fluorinated functional polymers and fluorinated hybrid polymers may be enabled by performing these reactions with a wide variety of organic compounds possessing carbon-hydrogen bonds as functional groups. One of the reviewers commented on the manuscript concerning the radical polyaddition of BFP with 1,4-dioxane that 'it describes unusual chemistry-it looks like a first step into a new field.' The reviewer must have been a sophisticated chemist with a philosophical mind.

\section{FACILE CARBON-CARBON BOND FORMATION AIDED BY FLUORINE SUBSTITUENTS}

One of the most important organic reactions would be a carboncarbon bond formation reaction. The successful achievement of a carbon-carbon bond formation reaction would be transformative for the field of organic chemistry. This would represent a key strategy for organic syntheses, allowing the molding of a carbon framework according to the desired specifications. Fluoroalkylation is one of the carbon-carbon bond formation reactions and has been achieved by reacting polyfluorinated vinyl compounds such as tetrafluoroethylene, chlorotrifluoroethylene and perfluorocyclobutene with ethers, alcohols and amines under radical conditions, although lowmolecular-weight oligomers are yielded simultaneously in the case of tetrafluoroethylene and chlorotrifluoroethylene. ${ }^{4}$ The high radical addition reactivity of the perfluoroisopropenyl group would also enable a novel fluoroalkylation to form carbon-carbon bonds accompanied by the introduction of fluoroalkyl groups into organic compounds. The reaction could be developed to enable the preparation of polymers. ${ }^{5,10}$

BPFP is a good candidate to participate in radical addition reactions with alcohols and ethers to form carbon-carbon bonds, as it is a good radical acceptor. The radical addition of BPFP with ethanol and 1-methylethanol yielded the corresponding fluorinated alcohols in high yields, as shown in Equation (18). 2-Trifluoromethylacrylates possessing these fluorinated alcohols as ester groups were synthesized by the reaction of 2-trifluoromethylacryloyl chloride with these alcohols, as also depicted in Equation (18). 2-Trifluoromethylacryloyl chloride was obtained by the reaction of 2-trifluoromethylacrylic acid with phthaloyl dichloride, and standard chlorination reagents did not work well to produce 2-trifluoromethylacrylic acid anhydride instead of acid chloride.

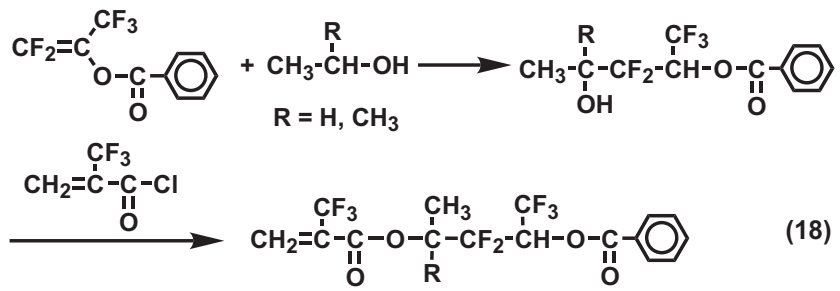

The radical addition of BPFP was also performed with tetrahydrofuran, 1,3-dioxolane and tetrahydropyran. The product of BPFP with tetrahydrofuran was a fluoroalkyl benzoate possessing the tetrahydrofuran moiety in the ester alkyl group $\left(\left(\mathrm{C}_{4} \mathrm{H}_{7} \mathrm{O}\right) \mathrm{CF}_{2} \mathrm{CH}\left(\mathrm{CF}_{3}\right)\right.$ $\left.\mathrm{OCOC}_{6} \mathrm{H}_{5}\right)$, which yielded the fluorinated alcohol $\left(\left(\mathrm{C}_{4} \mathrm{H}_{7} \mathrm{O}\right) \mathrm{CF}_{2} \mathrm{CH}\right.$ $\left.\left(\mathrm{CF}_{3}\right) \mathrm{OH}\right)$ by hydrolysis with sodium hydroxide. 2-Trifluoromethylacrylate was synthesized by the reaction of 2-trifluoromethylacryloyl chloride with the alcohol. The polymer of the 2-trifluoromethylacrylate derivative was obtained in low yield with $1.1 \times 10^{4}$ as the maximum molecular weight when the polymerization was initiated with benzoyl peroxide and allowed to proceed at $60{ }^{\circ} \mathrm{C}$ for $72 \mathrm{~h}$. Ethyl 2-trifluoromethylacrylate yielded no polymer under similar conditions but did produce the polymer under anionic conditions, as mentioned above (Table 2). The reaction profile is presented in Scheme $7 .^{5}$ Similar results were obtained by syntheses and polymerizations of 2-trifluoromethylacrylates possessing 1,3-dioxolane or tetrahydropyran moieties.

Acrylates and methacrylates possessing cyclic ether moieties in fluoroalkyl groups in ester moieties were also synthesized by reaction profiles similar to Scheme 7, and the corresponding homopolymers were successfully obtained in high yields under radical conditions. Polymers of 2-trifluoromethylacrylates, acrylates and methacrylates possessing fluoroalkyl groups bearing cyclic structures might be applicable to photoresist lithography.

The addition of fluorinated vinyl compounds to organic compounds possessing carbonyl groups besides carbon-hydrogen bonds has not been previously reported. The addition reactions of BPFP were examined with diethyl carbonate, dipropyl carbonate, ethyl methyl carbonate, dibenzyl carbonate and ethylene carbonate. The reactivity of BPFP with diethyl carbonate was found to be lower than that of tetrahydrofuran and 1,4-dioxane, as the yield was 53\% when the reaction was initiated with benzoyl peroxide. The reaction was found to take place as shown in Equation (19) by NMR and gas chromatography-mass spectrometry measurements of the product. The reaction takes place predominantly at the methylene group. Diethyl carbonate is then monofunctional, similar to tetrahydrofuran. This might be the first example of the addition of an organic compound bearing a carbonyl group onto a polyfluorinated vinyl compound, although the isolated yield was relatively low. The reaction is unlikely to be successful in preparing a polymer because carbonates basically perform as monofunctional compounds.

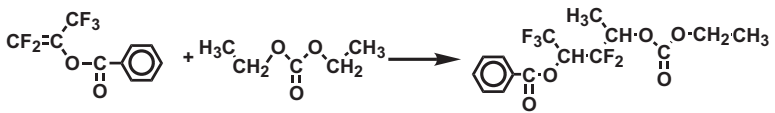




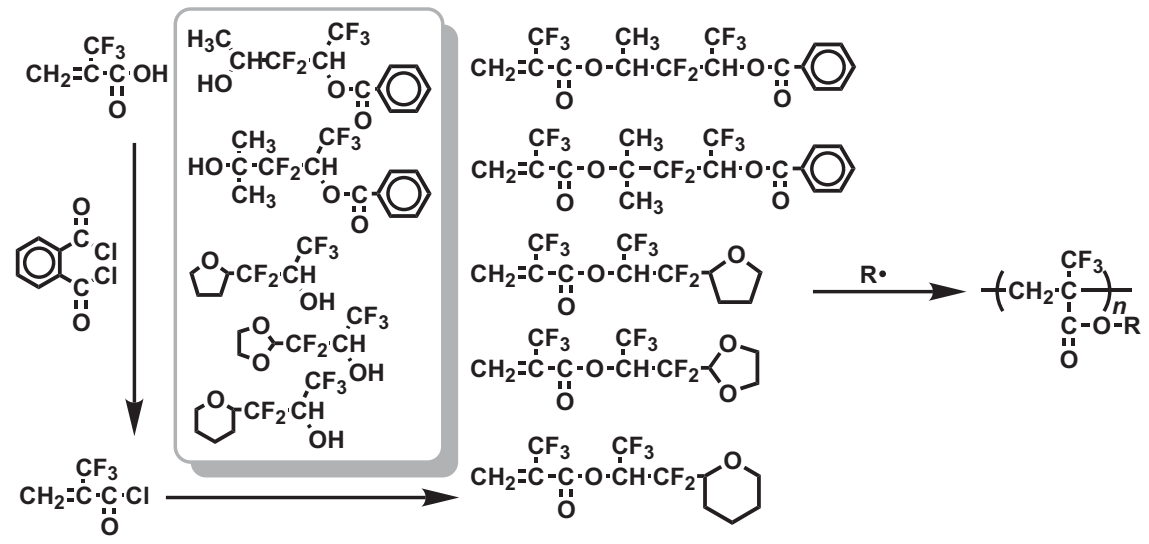

Scheme 7 Reaction profile of the synthesis and polymerization of novel 2-trifluoromethylacrylates.

The radical addition of heptafluoropropyl trifluorovinyl ether $\left(\mathrm{CF}_{2}=\mathrm{CF}-\mathrm{O}-\mathrm{C}_{3} \mathrm{~F}_{7}\right)$ with tetrahydrofuran, tetrahydropyran, 1,4-dioxane and 1,3-dioxolane was investigated to produce the corresponding 1:1 addition compounds in fairly high yields. The reactions were found to take place as shown in Equations (20-23). The reaction may be applicable to the preparation of polymers by the polyaddition of $\alpha, \omega$-bis(perfluorovinyl) compounds.

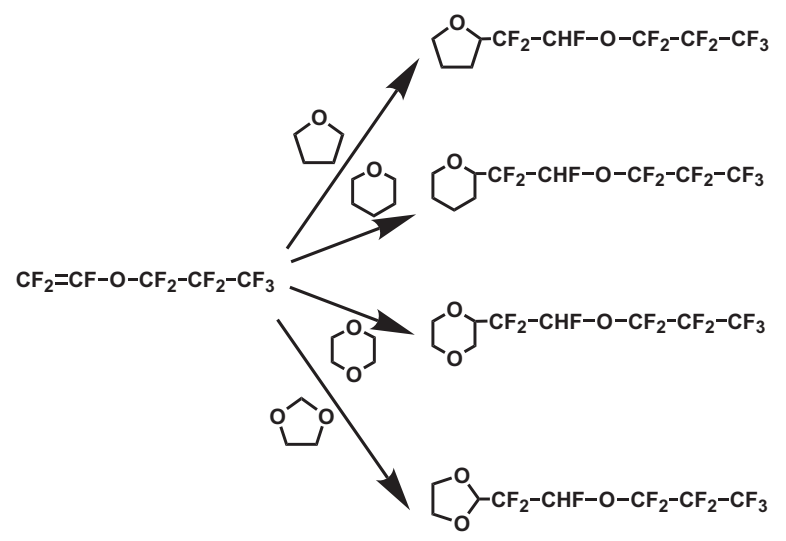

It is important to investigate how many fluorines in a vinyl group are needed for a radical addition reaction because hydrocarbon analogs such as acrylates, methacrylates and vinyl esters generally produce polymers instead of addition products under radical conditions. The addition reaction of 2-trifluoromethylacrylate could indicate how many fluorines are needed for radical addition reactions to form carbon-carbon bonds instead of polymers. The reaction of tert-butyl 2-trifluoromethylacrylate was examined with tetrahydrofuran, tetrahydropyran, 1,4-dioxane, 1,3-dioxolane, ethanol and 1methylethanol. The reactions were found to yield 1:1 addition products in high yields, as summarized in Scheme $8 .^{5}$ The results of the investigation are described for the polyaddition of bis(2-trifluoromethylacrylate) in the next section.

The synthesis of a novel organic compound could be achieved by the decomposition of a polymer formed by the radical polyaddition of bifunctional fluorinated vinyl monomers with several organic compounds because the polyaddition takes place through the precise radical shift mechanism to form novel carbon-carbon bonds as previously mentioned. The potential of the idea was examined by hydrolyzing the polymer obtained from BFP with tetraethoxysilane as shown in Equation (24), although the product yields were rather low. However, these products might be difficult to synthesize by standard organic synthetic methods.

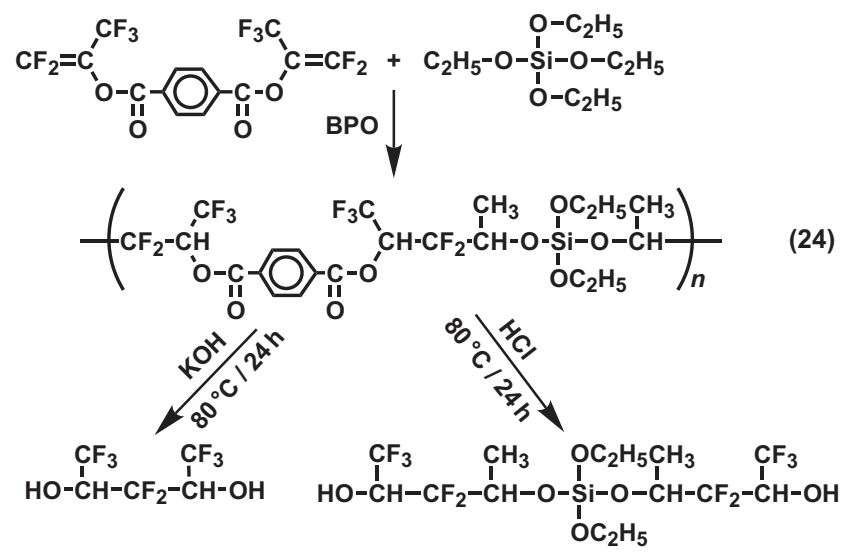

In the case of the hydrolysis of the polymer obtained from BFP with 18 -crown-6, several products were detected but could not allow the structural analyses of a di-addition product of 18-crown- 6 to be determined, as depicted in Equation (25). The 1,5-radical shift mechanism could be proven if the structure of the di-addition product was determined. Novel fluorinated organic compounds, which could not be synthesized by standard organic synthetic methods, were yielded by the decomposition of the polymers, thus demonstrating that radical polyaddition can be used to form new carbon-carbon bonds.

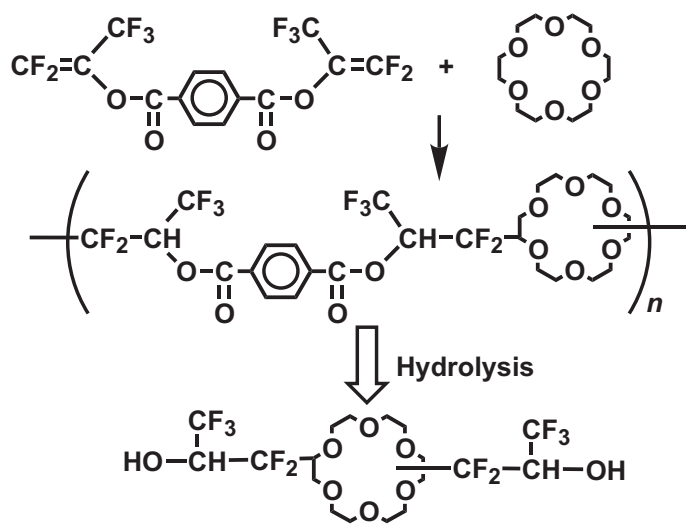




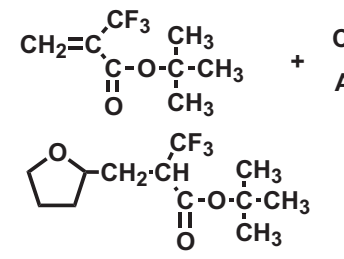

Mw: 268; bp: $88.4^{\circ} \mathrm{C} / 3 \mathrm{mmHg}$ Yield: $68.9 \%$; Purity: $100 \%$<smiles>CC(C)(C)OC(=O)C(CC1OCCO1)C(F)(F)F</smiles>

Mw: 270 ; bp: $78.0^{\circ} \mathrm{C} / 1 \mathrm{mmHg}$ Yield: $63.3 \%$; Purity: $95.8 \%$

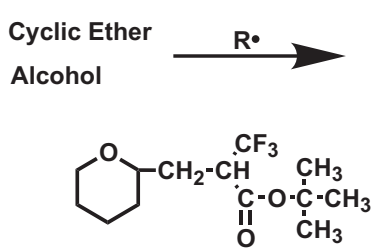

Mw: 282; bp: $64.0^{\circ} \mathrm{C} / 1 \mathrm{mmHg}$ Yield: 1.9\%; Purity: $93 \%$

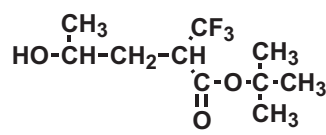

Mw: 242 ; bp: $68.5^{\circ} \mathrm{C} / 1 \mathrm{mmHg}$
Yield: $22.6 \%$; Purity: $98.3 \%$

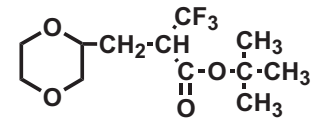

Mw: 284; bp: $75.5^{\circ} \mathrm{C} / 1 \mathrm{mmHg}$ Yield: $4.2 \%$; Purity: $95.1 \%$

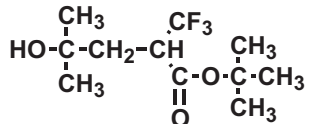

Mw: 256; bp: $65.2^{\circ} \mathrm{C} / 1 \mathrm{mmHg}$

Yield: $46.8 \%$; Purity: $100 \%$

Scheme 8 Radical addition of 2-trifluoromethylacrylate.

Facile carbon-carbon bond formation can be accomplished by using polyfluorinated vinyl compounds. such as BPFP, BFP, heptafluoropropyl trifluorovinyl ether and 2-trifluoromethylacrylates, which are all easily available. The fluoroalkylation described here would enable the synthesis of a wide variety of novel fluorinated polymers with aliphatic organic compounds bearing carbon-hydrogen bonds as functional groups. Organic syntheses through polymerization might also be successful because the controlled carbon-carbon bond formation was achieved by radical polyaddition reactions accompanied by the introduction of fluoroalkyl groups.

\section{SERENDIPITY}

The reactivity of fluorinated vinyl compounds often surprises organic chemists, particularly the variety of unexpected results demonstrated based on their reactivity. Serendipity has, generally, a role in the progress of science, and it has had an important one in fluorine chemistry in particular. For example, the radical addition polymerization of 2-trifluoromethylacrylates possessing long alkyl groups bearing cyclic ether moieties and the allyl polymerization of 4-pentenoyloxypentafluoropropene to produce high-molecular-weight polymers instead of cyclopolymerization, both arose in unexpected ways as mentioned above. Some of the other unexpected results are introduced in this section.

The radical polyaddition of bis(2-trifluoromethylacrylate) was investigated to develop a radical addition reaction with 2-trifluoromethylacrylates because they are good radical acceptors for the formation of addition products of alcohols and cyclic ethers as shown in Scheme 8. The radical addition of ethylene bis(2-trifluoromethylacrylate $\quad\left(\mathrm{CH}_{2}=\mathrm{C}\left(\mathrm{CF}_{3}\right) \mathrm{COO}-\mathrm{CH}_{2} \mathrm{CH}_{2}-\mathrm{OCOC}\left(\mathrm{CF}_{3}\right)=\mathrm{CH}_{2}\right)$ with tetrahydrofuran initiated by benzoyl peroxide produced the diaddition compound of ethylene bis(2-trifluoromethylacrylate) bearing two tetrahydrofuran moieties in $47 \%$ yield, and in contrast to the anticipation the oligomer of 2-trifluoromethylacrylate was produced with a molecular weight of $2 \times 10^{3}$ in $11 \%$ yield. No polyaddition reaction took place in the presence of an excess of 1,4-dioxane, as shown in Scheme 9. Instead, the homopolymer of 2-trifluoromethylacrylate was produced in $17 \%$ yield by the vinyl polymerization. The main product of the addition polymerization was a homopolymer of 2-trifluoromethylacrylate possessing 1,4-dioxane moieties linked to the other ends of 2-trifluoromethylacrylate moieties in 50\% yield. This may have arisen from the presence of a large substituent at the propagating chain end in the addition polymerization reaction, resulting in the stabilization of propagating radicals.
The homopolymerization of heptafluoropropyl trifluorovinyl ether has not been previously reported, whereas many articles have been published on alternating copolymers with hydrocarbon analogs under radical conditions. In the course of the investigation on the radical addition of heptafluoropropyl trifluorovinyl ether with alcohols and cyclic ethers as mentioned above, the study started on alternating copolymer syntheses under radical conditions with hexafluoroacetone instead of ordinary hydrocarbon analogs. ${ }^{5}$ None of the attempts were successful in producing an alternating copolymer. Furthermore, the reaction was carried out under $\gamma$-rays irradiation, demonstrating that the concentration of heptafluoropropyl trifluorovinyl ether decreased to yield a highly viscous oil-like pine resin. The irradiation of heptafluoropropyl trifluorovinyl ether was examined without hexafluoroacetone under $\gamma$-rays, thus demonstrating that the conversion of heptafluoropropyl trifluorovinyl ether and the product yields both increased with an increase in the irradiation dose. The product was partly soluble in hexafluorobenzene and insoluble in standard organic solvents. Therefore, the ability to analyze the product was restricted. The $5 \%$ weight-loss temperature $\left(T_{\mathrm{d} 5}\right)$ was $144^{\circ} \mathrm{C}$ for the polymer produced at $250 \mathrm{kGy}, 169^{\circ} \mathrm{C}$ at $500 \mathrm{kGy}$ and $165^{\circ} \mathrm{C}$ at $1000 \mathrm{kGy}$. The results suggested that the molecular weight would presumably increase with respect to irradiation dose, as the $T_{\mathrm{d} 5}$ values should be roughly proportional to the molecular weights of polymers. Higher doses of irradiation over $1000 \mathrm{kGy}$ resulted in a decrease in $T_{\mathrm{d} 5}$, with $156^{\circ} \mathrm{C}$ at $2000 \mathrm{kGy}, 144^{\circ} \mathrm{C}$ at $3000 \mathrm{kGy}$ and $130^{\circ} \mathrm{C}$ at $7400 \mathrm{kGy}$. These results suggest the formation of lower-molecular-weight products at higher doses or the degradation of synthesized polymers. The measurement of the viscosity of the hexafluorobenzene-soluble part obtained at $2000 \mathrm{kGy}$ was as high as $[\eta]=0.47$. Thus $\gamma$-rays irradiation was concluded to produce the homopolymer of heptafluoropropyl trifluorovinyl ether, as proven by ${ }^{13} \mathrm{C} \mathrm{NMR}$ measurements and diffusion reflection infrared spectra of the hexafluorobenzene-soluble portion of the product.

To incorporate fluorinated vinyl monomers into polymer main chains, radical copolymerizations are a common method with vinyl ethers, which generally yield homopolymers under a cationic polymerization condition. Another investigation on the synthesis of alternating copolymers of BPFP was attempted under radical reaction conditions with vinyl ethers. The radical copolymerization of BPFP with butyl vinyl ether was initiated with benzoyl peroxide. Polymers were produced in benzene as the polymerization solvent in low yields at $80^{\circ} \mathrm{C}$, although no polymer was obtained in the absence of solvent added. The ${ }^{1} \mathrm{H}$ NMR of the product showed no absorptions of the 


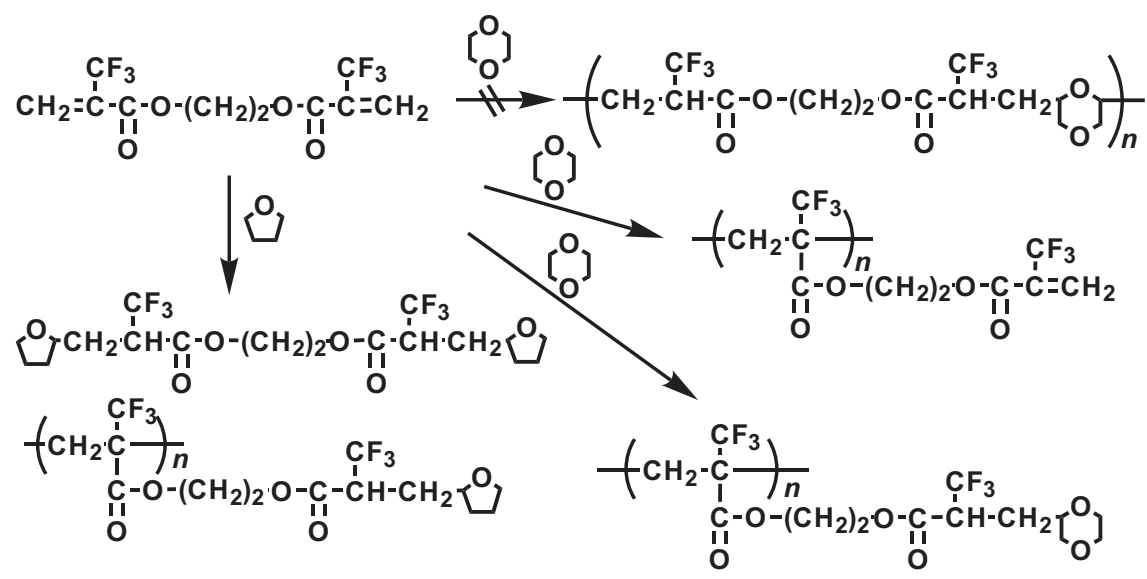

Scheme 9 Radical reaction profile of ethylene bis(2-trifluoromethylacrylate).

phenyl protons of BPFP moieties, and the spectrum was in accordance with that of the homopolymer of butyl vinyl ether produced under traditional cationic conditions. The polymerization was investigated at a low temperature because the homopolymerization of butyl vinyl ether is known to take place through a cationic mechanism at a lower temperature. High yields of poly(butyl vinyl ether) were obtained at both 0 and $-78^{\circ} \mathrm{C}$. The polymerization was then examined in the absence of benzoyl peroxide. Poly(butyl vinyl ether) was obtained in high yields with $1.6 \times 10^{5}$ as the highest molecular weight. A trace amount of the polymer was obtained without the addition of BPFP. This clearly suggested that BPFP performed as an initiator of the cationic polymerization. Similar results were obtained by the addition of BFP. Another example is the polymerization of $N$-vinylcarbazole, a compound known to produce a homopolymer only under cationic conditions. The polymer yields increased with an increase in the amount of BPFP added to the reaction system at 0 and $-78^{\circ} \mathrm{C}$, and poly $\left(N\right.$-vinylcarbazole) was yielded with $5.2 \times 10^{4}$ as the highest molecular weight. The polymer was produced with a small amount of BPFP added (even at $1 \mathrm{~mol} \%$ ). These results confirm that the addition of BPFP does yield some cationic species. No evidence was found on the initiation by hydrogen fluoride, ${ }^{5}$ and no other information has since been obtained on the mechanism of the cationic polymerization in the presence of BPFP.

The polymerization of 1,1,2-trifluoro-1,3-butadiene $\left(\mathrm{CF}_{2}=\mathrm{CF}-\right.$ $\mathrm{CH}=\mathrm{CH}_{2}$ ) was more peculiar than that of butyl vinyl ether. The compound was difficult to store at $-20^{\circ} \mathrm{C}$ because a white powdery substance formed within a few hours. The observation suggested that a reaction would take place in the presence of a trace amount of water. The polymer was actually obtained at $60{ }^{\circ} \mathrm{C}$ for $96 \mathrm{~h}$ in $60 \%$ yield by the initiation of water, which is the least active initiator of anionic polymerization. The polymer showed a unimodal molecular weight distribution with a molecular weight of about $10^{5} .{ }^{1} \mathrm{H}$ NMR spectra of the polymer revealed that a head-to-head (or tail-to-tail) addition reaction took place along with a large amount of 1,4-addition polymer as shown in Equation (26). The copolymerization of 1,1,2-trifluoro-1, 3-butadiene was found to produce copolymers with styrene initiated with water. Styrene was incorporated into a copolymer main chain initiated by water. The monomer reactivity ratios of 1,1,2-trifluoro1,3-butadiene $\left(\mathrm{M}_{1}\right)$ and styrene $\left(\mathrm{M}_{2}\right)$ were as follows: $r_{1}=0.76$ and $r_{2}=0.45$ when initiated by water, $r_{1}=0.63$ and $r_{2}=0.39$ by sec $-\mathrm{C}_{4} \mathrm{H}_{9} \mathrm{Li}$ and $r_{1}=0.53$ and $r_{2}=0.15$ by $2,2^{\prime}$-azobisisobutyronitrile. The $Q$ and $e$ values were calculated to be 1.86 and 0.79 , respectively. The monomer might, therefore, be a conjugated compound. These results suggested that the polymerization mechanism initiated with water should be different from that initiated with sec- $\mathrm{C}_{4} \mathrm{H}_{9} \mathrm{Li}$ and $2,2^{\prime}$-azobisisobutyronitrile, meaning that the polymerization reaction mechanism would be different from typical anionic and radical mechanisms. The results were also supported by the fact that the poly(1,1,2-trifluoro-1, 3-butadiene) was obtained in the presence of tert-butylcatechol. The polymerization of 1,1,2-trifluoro-1,3-butadiene was unhappily declined for publication, probably because the results seemed to be an unusual chemistry beyond serendipity.

$\mathrm{CF}_{2}=\mathrm{CF}-\mathrm{CH}=\mathrm{CH}_{2} \longrightarrow-\left(\mathrm{CF}_{2}-\mathrm{CF}=\mathrm{CH}-\mathrm{CH}_{2}\right)_{m}\left(\mathrm{CH}_{2}-\mathrm{CH}=\mathrm{CF}-\mathrm{CF}_{2}\right)_{n}$

A great deal of serendipity has been involved in the development of organofluorine chemistry, more so than that involved in usual organic syntheses and macromolecular chemistry, probably because the broad field seems to remain open.

\section{CONCLUSION}

The high addition reactivity of fluorinated vinyl compounds toward anionic and radical species was demonstrated to afford facile methods for the preparation of carbon-carbon bonds and novel fluorinated polymers. The anionic addition polymerization of a wide range of fluorinated vinyl monomers was investigated to provide clear evidence that fluorine substituents have an important role in elevating the reactivity toward anionic species. The reactivity of an acrylate or a methacrylate possessing a fluoroalkyl group in an ester moiety was markedly enhanced, allowing polymer synthesis by initiators of relatively low reactivity such as organoaluminums. The anionic addition polymerization reactivity of alkyl 2-trifluoromethylacrylate was greatly enhanced and that of fluoroalkyl 2-trifluoromethylacrylates was decreased. Poly(hexafluoro-1,3-butadiene) was obtained by the initiation of cesium derivatives to afford a polymer with a higher thermostability compared with poly(tetrafluoroethylene). A quantitative study was conducted on the initiation reactivity of 18 fluorinated acrylates and methacrylates by the measurements of pseudo first-order rate constants with diethyl(ethyl cyanoacetato)aluminum to determine the order of reactivity to anionic species. These findings represent fundamental information that allows a theoretical analysis of the observed reactivities. The new field, anionic polyaddition, was proposed by the reaction of 2-trifluoromethylacrylates with active 
methylene compounds. Good acceptors of radical species were developed to achieve radical polyaddition of fluorinated vinyl monomers with organic compounds possessing carbon-hydrogen bonds. These reactions also enabled facile carbon-carbon bond formation aided by fluorine substituents accompanied by the introduction of fluoroalkyl groups into organic compounds. A carbon-hydrogen bond as a functional group represents enormous potential for carbon-carbon bond formation in aliphatic compounds. It is important to knock on the door of the house of each fluorinated vinyl compound in order to ask how the resident wants to act and accumulate the statements from the academic point of view. ${ }^{2}$ The incorporation of these fluorinated vinyl monomers into polymer main chains presents real enthusiasm for the development of novel long-lived propagating chain ends. Chemistry starts from syntheses. Run a risk, and you can be the one and only.

The review on the work of one fluorine chemist to leave it on the sands of time is meant to invite newcomers to this field of research as the author challenged to do about 30 years ago. As a macromolecular synthetic chemist, it provides me great pleasure to be able to describe so many chemical equations. The door is still wide open in the area of research, as many proposals presented here have not yet been completed. The subject is in excellent young hands and is worthy of a life's work. Fluorine is a 'small atom with a big ego.'11

\section{ACKNOWLEDGEMENTS}

I am very much indebted to many of my co-workers and students whose enthusiasm and hard work have made these developments possible. I appreciate the courtesy of the many companies that provided fluorinated and organosilicone compounds. I express my gratitude to many foundations for their financial support, especially to the 'Nissan Science Foundation', 'The Shinsei Foundation', 'The Mazda Foundation', 'The High-Tech Research Center Project of Private Universities: matching fund subsidy, 1999-2008' and the 'Open Research Center, 2007-2009' Project of Saitama Institute of Technology from the Ministry of Education, Culture, Sports, Science and Technology of Japan. I am deeply indebted to Professor Emeritus Teiji Tsuruta for his continuous encouragement and discussion throughout this work. This article is dedicated to Mrs Mieko Narita, who has supported my family and research life for more than 42 years.
This is a review based on an invited lecture at the 59th Symposium on Macromolecules organized by the Society of Polymer Science, Japan, held at Sapporo in September 2010. Part of the review was presented in the Polymer Preprints, Japan, 59(2), 4707-4709 (2010).

1 Wall, L. A. (ed.) Fluoropolymers (Wiley-Interscience, New York, 1972).

2 Narita, T. Anionic polymerization of fluorinated vinyl monomers. Prog. Polym. Sci. 24, 1095-1148 (1999).

3 Narita, T. On the polymerization reactivity of fluorinated vinyl monomers. Macromol. Rapid Commun. 21, 613-627 (2000).

4 Chambers, R. D. (ed) Organofluorine Chemistry_Fluorinated Alkenes and Reactive Intermediates (Springer, Berlin, 1997).

5 Narita, T. Stimulation on the addition reactivity of fluorinated vinyl monomers-facile carbon-carbon bond formation by the aid of fluorine substituents. J. Fluorine Chem. $131,812-828$ (2010).

6 Smith, D. W. Jr \& Babb, D. A. Perfluorocyclobutene aromatic polyethers. Synthesis and characterization of new siloxane-containing fluoropolymers. Macromolecules 29, 852-860 (1996).

7 Chang, C. H., Andreassen, A. L. \& Bauer, D. H. The molecular structure of perfluorbutyne-2 and perfluorobutadiene-1,3 as studied by gas phase electron diffraction. J. Org. Chem. 36, 920-923 (1971).

8 Umino, Y., Narita, T. \& Hamana, $\mathrm{H}$. Initiation reactivity of anionic polymerization of fluorinated acrylates and methacrylates with diethyl(ethyl cyanoacetato)aluminum. J. Polym. Sci. A Polym. Chem. 46, 7011-7021 (2008).

9 Umino, $Y$, Nozaki, $H$, Hamana, $H$. \& Narita, $T$. Novel anionic polyaddition of 2-trifluoromethylacrylate by double Michael reaction with ethyl cyanoacetate. J. Polym. Sci. A Polym. Chem. 47, 5698-5708 (2009).

10 Narita, T. Novel fluorinated polymers by radical polyaddition: inspiration and progress. J. Polym. Sci. A Polym. Chem. 42, 4101-4125 (2004).

11 The logotype of ACS symposium (San Francisco, USA, 2000).

12 Narita, T., Hagiwara, T., Hamana, H. \& Nara, T. Anionic polymerization of ethyl 2-trifluoromethylacrylate. Makromol. Chem. Rapid Commun. 6, 301-304 (1985).

13 Ito, H., Miller, D. C. \& Willson, C. G. Polymerization of methyl $\alpha$-(trifluoromethyl)acrylate and $\alpha$-(trifluoromethyl)acrylonitrile and copolymerization of these monomers with methyl methacrylate. Macromolecules 15, 915-920 (1982).

14 Narita, T., Hagiwara, T., Hamana, H. \& Maesaka, S. Anionic polymerization of fluoroalkyl 2-trifluoromethylacrylates. Polym. J. 20, 519-523 (1988).

15 Hosoya, A., Hamana, H. \& Narita, T. PhD Thesis (2010).

16 Hosoya, A., Yoshimoto, A., Hamana, H. \& Narita, T. Graduation Research (2008).

17 Hosoya, A., Takani, A., Hamana, H. \& Narita, T. Graduation Research (2009).

18 Hosoya, A., Igarashi, T., Hamana, H. \& Narita, T. Graduation Research (2009).

19 Kurakami, G., Hosoya, A., Hamana, H. \& Narita, T. J. Synthesis and polymerization of novel bis(2-trifluoromethylacrylate). J. Polym. Sci. A Polym. 48, 2722-2724 (2010).

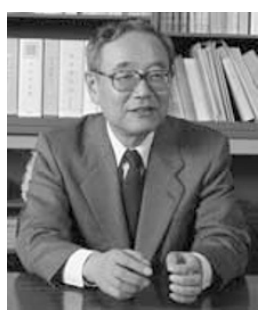

Dr Tadashi Narita received his Bachelor of Engineering in 1963 from Yokohama National University. He received his Master of Engineering degree in 1965 and his Ph.D. in 1970, both from the University of Tokyo, Faculty of Engineering. Dr Narita started his academic career in 1968 at the University of Tokyo and moved to Saitama Institute of Technology in 1976. He was full-time professor by 1983. Dr Narita's major interest is in the synthetic chemistry of polymers, especially in the field of anionic polymerization and radical polyaddition of fluorinated vinyl monomers. Dr Narita published many articles in prestigious journals such as Polymer Journal, Kobunshi Ronbunshu, Bulletin of Chemical Society of Japan, Journal of Macromolecular Science-Chemistry, Journal of Organometallic Chemistry, Makromolekulare Chemie, Macromolecular Chemistry and Physics, Journal of Polymer Science: Part A: Polymer Chemistry, Macromolecules, Journal of Fluorine Chemistry, Collection of Czechoslovak Chemical Communications, Chemical Communications and Reactive and Functional Polymers. Dr Narita published nine books written in English and reviewed a great number of articles in his field of expertise and he was a guest lecturer both in Japan and abroad. 